\title{
Del golpe de agosto-1991 a los programas de ajuste estructural en la URSS
}

\author{
Lic. Fco. Javier Ibisate
}

\section{Un golpe ¿contra quién?}

Pocas veces hemos presenciado, en el lapso de una semana, una secuencia de hechos que hayan mantenido tan en vilo la atención mundial y que hayan podido afectar tan seriamente al nuevo orden internacional. El golpe comunista fué detenido por el mismo pueblo, pero permanecen las causales con que se le quiso legitimar, y queda por delante la multipolar tarea de construir la democracia. De todas maneras ¿por qué distraernos hablando y escribiendo sobre un golpe que ya pasó y sobre una lejana reconstrucción cuando estamos empenados en poner fin a nuestro propio golpe e iniciar nuestra reconstrucción, sin que el opulento Occidente se preocupe tanto por nosotros? -Esta es precisamente la razón: ¿cómo vamos a realizar nuestra propia reconstrucción?- De hecho también a nosotros se nos impone el mismo programa de ajuste estructural, la misma economia de mercado, como el sólido puente hacia el bienestar, tanto más que los regimenes socialistas ya han fracasado y no queda otra salida. Dado que en una sociedad democrática hay derecho a expresar y aclarar los términos y las ideas, y que además del blanco y negro existen otros colores, conviene preguntarnos quién dió el golpe y contra quién. La respuesta es: "un golpe que se hiere a si mismo".

El fracaso del golpe moscovita y el rechazo popular a los grupos representados por los ocho "halcones" no significa el exterminio del socialismo, sino el repudio a un determinado partido comunista, en ningu- 
na manera socialista. Desde la década de los sesenta, sobre todo a raiz de la invasión a Checoeslovaquia (1968), muchos autores y movimientos socialistas, inicialmente favorables a la revolución de octubre-1917, comenzaron a poner en entredicho el carácter socialista del comunismo soviético. El entredicho se formulaba de la siguiente manera: para saber lo que es socialismo tenemos que analizar to que no es socialismo. Frente a las economias del Este se planteaban tres preguntas: ¿esas economias son socialistas?; ¿lo han sido alguna vez?; ¿llegarán algun día a ser socialistas? -Las respuestas variaban sólo en el calificativo: esas economias no son capitalismo, tampoco son socialismo; son Estados Colectivistas, Capitalismo de Estado, Regimenes Burocráticos, Economias en transición..., de acuerdo a los diversos autores.

Una persona que en forma precipitada y dolorosa aprende la lección es el propio M. Gorbachov. En su Perestroika y en su informe al Pleno del Partido (1987) descubre con toda crudeza y sinceridad la decadencia política y económica a que el partido habia conducido a la nación. El define la reestructuración como: "más socialismo, más democracia", y su gran error fué creer que podia ganar al partido comunista para la lucha en favor de la democracia. Los ocho golpistas son personajes de segunda categoria, aupados por el mismo Gorbachov; representantes del ala conservadora del partido, del ejército y de la industria bélica-militar lo traicionan e intentan derrocar al socialismo democrático. Como lo decimos más adelante, el golpe se esperaba para finales de ano. Algo tenian que hacer los supervivientes del partido cuando la misma Academia de Ciencias de la URSS publicaba los "nuevos estudios y enfoques sobre la historia rusa y soviética"' que da inicio a todo el proceso de depuración estalinista. En los foros internacionales (Barcelona, 1988; Moscú, 1989; La Sorona, París, 1990...) pensadores del Este-Oeste europeo rechazaban la auténtica socialista que había querido monopolizar el partido comunista soviético. Por anadidura, la dirigencia del partido debia renovar las mayores resistencias a las reformas económicas, como to hicieron en las pasadas perestroikas (1955..., 1965...), sobre todo que ahora se sentenciaba la suerte del partido con el Tratado de la Unión.

Por lo tanto, no es el socialismo, sino su oponente el partido comunista soviético quien pasa al banquillo de los acusados. De principio a final del siglo se cambian los papeles de acusado y acusador. Si a partir de 1917 la dirigencia del partido comunista de la URSS desprestigiaba

1. Ibisate Fco. Javier: "Los socialismos reales hacen su propia autocrítica". ECA. Julio-agosto, 1991; pp. 679...

¿¿Hacia dónde va el Este? y ¿hacia dónde va el Oeste? -Realidad Económico-Social. Enero-febrero, 1990; pp. 33... 
al resto de movimientos socialistas como "social-traidores" (ECA, 1991; pp. 689-690), ahora al terminar el siglo, los movimientos socialista europeos congregados en el foro de La Sorbona 1990, le devuelven el boomerang:" el voluntarismo de la Lenín sólo podia conducir a una dictadura duradera sobre el proletariado; sólo la democracia política permite conocer la voluntad popular; la democracia no puede ser sólo un medio, sino un fin. La oposición que de ahi derivó entre el comunismo y el socialismo fué irreductible en el fondo". (Realidad Económica; 1990; p. 35). La controversia y la alternativa al interior de la URSS y del bloqueEste no es propiamente una lucha y una elección entre socialismo y capitalismo, sino entre comunismo soviético dictatorial y socialismo democrático.

Tampoco se trata de un enfrentamiento y de una elección entre plan - mercado, puesto que plan y mercado son dos componentes del mecanismo económico del capitalismo y del socialismo democráticos. Mientras que el partido comunista, dentro y fuera de la URSS, desnaturalizó la función del plan, transformando un instrumento de política económica en el dictak de la economia política, imperializando la convivencia social. No es de extranar que autorizados socialistas europeos y norteamericanos (P. Sweezy, Ch. Bettelheim, M. Dobb, E. Mandel...), inicialmente defensores del modelo planificado soviético, se convirtieran tres décadas más tarde en sus más críticos acusadores." Durante mucho tiempo no se ha tenido en cuenta que puede existir una planificación y plan burgueses, lo mismo que puede existir una planificación y un plan proletario o socialista. Identificando plan con socialismo y mercado con capitalismo (lo cual es cierto como tendencia), se ayuda a la burguesía, especialmente a la burguesia soviética a ejercer su dominación al abrigo de un plan, en cuyo nombre retira todo derecho de expresión a las clases explotadas y con cuya ayuda puede agravar aun más la explotación de las masas.... Cuando el plan no es este "concentrado" (de las aspiraciones populares) es un plan burgués, y no un plan socialista; no es lo contrario del mercado, sino su complemento o su sustituto provisional. Esto que acabamos de decir ha sido en la práctica ignorado durante mucho tiempo, incluso por mi mismo". Ch. Bettelheim (ECA, 1991: pp. 702-703).

En las remodelaciones económicas presentadas secuencial o alternativamente en la URSS (propuestas Abalkin, Sathalin, Aganbegian, Yaulinsky...) no se trata de una transferencia de economia planificada a economía de simple mercado, sino de una equilibrada integración del mercado orientado por el plan. Basta leer el informe presentado por $\mathbf{A}$. Aganbegian, consejero de $M$. Gorbachov, cuyo resumen se ha integrado en anterior publicación. (ECA, 1991; pp. 705-709). El problema más se- 
rio está en otra parte. En los últimos seis anos de reestructuración económica la URSS no ha tenido ni plan ni mercado, de suerte que la declinación económica muy sensible desde 1975 (era-Bresnev) ha llegado al total desconcierto convirtiendo a la gran potencia en una nación mendicante. La situación es tan caótica que se teme (Shevardnadze) otro desesperado golpe de estado del ala conservadora antes de terminar el presente ano, aprovechando el desconcierto y la penuria económica generalizada. Sobre todo que la reforma económica es, en última instancia, una reforma y una lucha de poderes. Lucha de poderes entre el centro y las repúblicas, que parece inclinarse a favor de las últimas, logrando B. Yeltsin ganar a su causa al propia M. Gorbachov. Lucha de poderes entre quienes quisieran volver a controlar todo el poder desde el plan (partido centralista y movimiento "soyuz" = unión), y quienes buscan en el mercado empresarial la expresión democrática de la economia. Es en este sentido que el socialismo entiende que el mercador democrático es el lugar de expresión de la iniciativa, creatividad y liber $\sim^{-}$ tad personal que el plan central habia esterilizado durante setenta anos. La libertad económica para la producción civil surge a la par de la libertad de expresión cultural en todos los medios de comunicación social.

Resulta relativamente fácil trasladar a los diarios, televisión, teairo.... las nuevas ideas, las protestas y las sugerencias. Pero no es tarea fácil, ni del corto plazo, transferir todas las ramas y sectores productivos al engranaje del mercado intersectorial cuando se ha carecido de una e:periencia económica de los costos y precios reales, de crittrio', de selección de inversiones y créditos, del valor real de una moneda contable o transferible, pero no convertible, de las técnicas de comercialización interna e internacional e incluso de la calidad de los productos. Al estar todos estos mecanismos del mercado integrados y detallados en $=1$ plan, la transferencia de la producción civil a economia de mercad; resulta tan complicada como la transferencia de la industria bélico-militar a industria civil. Las dificultades, provenientes del antiguo régimen, se multiplican y no pueden resolverse desde dentro en el corto plazo. Como lo indican A. Aganbegian y G. Yaulinsky, los parámetros de esta reconversión tienen que venir desde fuera bajo forma de elevados créditos y tecnologia administrativa. Esta es parte de la crisis que el partido comunista ha gestado en la URSS. La verdadera y costosa transición es el paso del comunismo soviético hacia el socialismo democrático.

Toda esta problemática de las transiciones en la unión de Repúblicas Soberanas Soviéticas despierta una elevada dosis de curiosidad académica, de manera que lo que parece estar lejos está cerca de nosotros. Por anadidura se dan un conjunto de rasgos coincidentes entre su transición y la nuestra. Ahi esta el problema de la desmilitarización, no sólo 
cuantitativa por reducción numérica del ejército y gastos militares, sino cualitativamente en cuanto transición a una sociedad civilista y de estado de derecho. Está el problema de la depuración de los cuerpos de seguridad (KGB), de poner fin a la impunidad en la administración de justicia, el respeto a la dignidad y libertad de la persona..., y por extrano que parezca, allá y acá se repiten el mismo tipo de alianzas entre los poderosos que se oponen a las reformas democráticas. Estando lejos, estamos cerca; no se trata de elucubraciones teóricas sobre los modelos económicos, sino de lecciones prácticas para la transición hacia regimenes más democráticos. Con esta óptica merece la pena introducimos en el anecdotario de los sucesos soviéticos de la URSS.

\section{Un golpe contra un proceso}

En la noche del domingo 18 de agosto, época de vacaciones, se decide la destitución de $M$. Gorbachov, encausado de enfermo. Las coincidencias identifican las intenciones de los golpistas. Se repite la fecha dominical y la razón de salud de la destitución de B. Krutchev, 1964. Se repite la fecha dominical y vacacional de la invasión de Praga (21-08-68). La misma cronologia, las mismas razones y la misma táctica de los "halcones" en 1962, 1968 y 1991, que en las tres ocasiones se apresuran a nombrar un Comité Estatal de Emergencia. De manera especial se repiten las mismas razones: "la superación de la profunda crisis, el caos y la anarquia que amenazan la vida y la seguridad de los ciudadanos de la URSS, la libertad y la independenciade nuestra sociedad". En este primer mensaje de G. Yaneyev no se hace la menor mención a querer salvar los ideales del socialismo, conscientes de que con ese aditivo el complot hubiera abortado la misma manana del lunes. Se pulsan las mismas teclas patrióticas de siempre que, viniendo de donde vienen, disuenan como el peor autoengaño.

Los ocho golpistas, representantes del ala conservadora del partido, de la casta privilegiada del generalato militar y de la alta dirección de la industria bélico-militar, habian sido aupados a sus puestos directivos por el mismo $\mathrm{M}$. Goßbachov, creyendo poder ganarlos a su causa, y más bien provocando con ello el distanciamiento de sus mejores asesores e inspiradores, A. Yakolev, E. Shevardnadze, Shatalin, Grachov.... La traición de los suyos le ha convencido, muy a su pesar, que los dogmáticos son inconvertibles; siguiendo el ejemplo de B. Yeltsin en Rusia. M. Gorbachov anuncia el sabado 24 de agosto su dimisión como Secretario del Partido (PCUS), confisca todos sus bienes y prácticamente disuelve de un plumazo la institución monolítica que creara Lenin, al pedirles que ellos mismos se autodisuelvan. Realmente el golpe se hirió a si mismo. 
Antes de hilvanar algunas reflexiones sobre estos sucesos que dejaban en interrogante el nuevo orden internacional, vale la pena recordar ciertas reacciones más inmediatas. El martes 20 de agosto "el pánico sacudió las bolsas internacionales", que registraron importantes pérdidas mientras que sube el precio del dólar, del oro y el precio del petróleo roza los \$22. Dos días más tarde, el final trágico cómico del golpe provoca la recuperación en las bolsas de valores junto con la caida del dólar y del oro. En dirección contraria a la bolsa de valores, el sorpresivo golpe es amigablemente apreciado por Irak, Libia, la OLP, y con dominada alegria por China y Cuba. Dos días más tarde, los dirigentes chinos comentan lacónicamente: "se trata de asuntos internos", silenciando las referencias que se les hacen sobre los sucesos de la PlazaTiannamen. Aquí, en El Salvador, la reacción gubernamental fué realmente mediocre y cortometrista: los duros del nuevo régimen podrian alentar la ayuda militar a la guerrilla, vía la comunista Cuba. Parecería que esa era la gran tragedia mundial del golpe.

No dejo de llamar la atención cierta reacción favorable al golpe, encausando a M. Gorbachov como el culpable número uno del deterioro económico, y a B. Yeltsin como el divisionista de la Unión. Ni las realidades anteriores, ni los sucesos posteriores al golpe dan pie a este precipitado enjuiciamiento. Ahora, con un tiempo de espera, podemos reflexionar más serenamente sobre estos sucesos en la perspectiva de un nuevo orden mundial. El actor principal no fué el malogrado partido comunista-URSS. El actor principal ha sido el pueblo, que reclama democracia, libertad, decir la verdad, junto con la esperada atención a sus deterioradas necesidades económicas. El pueblo convenció al ejército a no disparar sobre la población, y el pueblo junto con soldados y militares rindieron el más concurrido homenaje a las tres víctimas, declarados héroes de la resistencia pacífica. Estos son sucesos de Moscú, Kiev y Leningrado.... Tenemos mucho que aprender de esta agitada semana.

\section{Un golpe esperado}

Comencemos por las vísperas del complot. Tres dias antes del complot, viernes 16 de agosto, Alexander Yakolev, ideólogo de la Perestroika y ex-consejero número-uno de $M$. Gorbachov, presenta su renuncia al PCUS y anuncia el golpe de Estado. Siguiendo el ejemplo de E. Shevardnadze, A. Rutskoi, Vicepresidente de Rusia, y tantos otros exconsejeros de Gorbachov, A. Yakolev justifica su renuncia:" "los estalinistas han conseguido gran influencia en el núcleo dirigente del PCUS y pretenden acabar con la línea política comenzada en 1985, frenando el progreso social del país. El PCUS se está convirtiendo con gran rapidez en el partido del revanchismo con la participación del ala conserva- 
dora, el aparato del complejo militar-industrial, el generalato y la dirección de las fuerzas de seguridad (Ministerio del Interior y KGB), que temen perder no solo el poder sino lo que éste lleva parejo. La dirección del PCUS se esta desprendiendo del ala democrática del partido y so está preparando para una revancha social y un gope de estado". El exconsejero de M. Gorbachov llega a la más drástica conclusión: "todos nuestros males tienen su origen en los dogmas del maxismo revolucionario y en la dictadura del proletariado basada en la violencia. Asi he llegado al rechazo del maxxismo y a la constatación de que el socialismo ha fracasado"2

Alexander Yakolev, uniéndose a similares declaraciones de sus colegas A. Grachov y B. Petrakov (ECA, 1991; p. 692-693), rechaza el modo socialista y la interpretación dogmática marxista imperante en la URSS, y funda con estos y otros socialistas democráticos la asociación (¿futuro partido) de la unión democrática Nacional. En entrevista a la agencia Novosti, A. Yakolev aseguró que habia pasado tres meses intentando convencer a Gorbachov, pero "lamentablemente, continúa creyendo en la posibilidad de modificar al PCUS desde dentro". El lider reformista dice desconocer si Gorbachov está o no al tanto de su expulsión y de to que está sucediendo al interior del PCUS." Por un lado, no me gustarla creer que está al corriente de la situación. Por otra parte, no seria mejor si realmente se encontrase al margen, ya que significaria que ha perdido el control del partido". ${ }^{2}$ Una vez fracasado el golpe, A. Yakolev comentará, en entrevista al diario Libération, que la actitud de $M$. Gorbachov en su conferencia de prensa fué decepcionante:" El Presidente ha demostrado que no comprendió lo que ocurrió realmente. Tal vez haya comprendido los hechos, pero no ha visto al pueblo movilizado y no ha querido distinguir inmediatamente entre las personas que ocupan cargos oficiales aquellos que se comportan bien de los que le traicionaron"... De hecho fué B. Yeltsin quien forzó a M. Gorbachov a destituir a los primeramente nombrados sustitutos del ministerio de defensa, de la dirección de la KGB, y a nombrar nuevas autoridades más afines a la línea democrática. Por ello agrega A. Yakolev: "M. Gorbachov y B. Yeltsin deben trabajar juntos".

Dato interesante es que hay un error de cálculo en la fecha en que $A$. Yakolev presagiara el golpe. En la misma entrevista a la agencia Novosti dice que "se aprovechará la reunión del $29^{\circ}$ Congreso Extraordinario del PCUS, a celebrarse en noviembre o diciembre, donde M. Gorbachov será ejecutado políticamente, destituido de su cargo de Secretario Ge-

2. El Correo Español. El Pueblo Vasco. 17-08-91; pp. 16 y 18. 
neral y expulsado del partido". No ha sido A. Yakolev el único sorprendido por la fecha-calendario. Tampoco los servicios de inteligencia occidentales funcionaron y el presidente $G$. Bush se enteró del golpe por la agencia TASS. La CIA y la DIA (Agencia de Inteligencia de la Defensa) habian previsto el golpe desde hacia tiempo, pero sus analistas creian que el intento "se llevaria a cabo en invierno, cuando la escasez de alimentos y calefacción provocaria manifestaciones y protestas populares contra Gorbachov. Tampoco los servicios de inteligencia de Alemania, Francia, Gran Bretana e incluso de Israel supieron analizar correctamente los movimientos en la URSS. ${ }^{3}$ El golpe se planeó en vacaciones.

Sin embargo habia una razón fundamental para escoger esta fecha. Gorvachov, que estaba de vacaciones, debia regresar a Moscú para firmar el Tratado de la Unión el día martes 20 de agosto. Para los ocho conspiradores del ala conservadora la firma del Tratado de la Unión venía a clausurar su era de poder onmimodo en la esfera política, económica, militar e ideológica. Eso explica la precipitación e improvisación del golpe, sin tiempo para ponderar los avances democráticos y las previsibles reacciones del pueblo, que habia perdido su incondicional fé en el partido. Los ocho conspiradores, se les ha calificado de "halcones", representaban los intereses amenazados de una troika que perdia su autoridad, prestigio y presupuesto económico tanto con las reformas como con el Tratado de la Unión.

A lo largo del año, a comenzar por E. Shevardnadze, ya se estaba anunciando que la reacción vendria de esa trilogía de los conservadores del partido, del alto generalato y de la dirección de la industria bélicomilitar. Más recientemente, agosto 1991, R. Sagdeved, director del programa de investigación espacial y consejero de Gorbachov en las cumbres del desarme, acusa "al complejo militar-industrial de la URSS de ser el verdadero instigador del golpe. Lo forman unos 15 millones de empleados y cuenta con una financiación que supone cerca del $25 \%$ del presupuesto del pais. Ellos dicen que es el sector más eficiente de la economia soviética, pero si tú les pidieras que reconvirtieran su eficacia en áreas civiles, serian incapaces de hacerlo Este choque cultural creó el sentimiento de que tenian que hacer algo. Tenian en mente una administración militarizada, sin compromisos ideológicos, que proporcionase mano dura y estabilidad. Subestimaron la decisión del pueblo de no dejarse intimidar ya más. Este fué su error de cálculo. Pensaban que la gente estaba aún infectada por el vinus del miedo e infravaloraron el cambio de mentalidad que se ha operado en la gente en los últimos

3. El País: 25-08-91; pp. 6-7. 
Varios analistas piensan que el cerebro de la junta golpista era Oleg Baklanov, hombre clave de la industria militar, al igual que A. Tiziakov, jefe de la asociación de las empresas estatales de la URSS. Los cerebros de la junta escogieron a tres personajes muy conocidos de la vida política: D. Yazov, Ministro de Defensa, V. Kriuchov. Presidente de la KGV y V. Paulov, Primer Ministro; todos aupados por M. Gorbachov. Se agrega un duro reconocido, B. Pugo, originario de la independiente Letonia, Ministro del Interior; se suicidó antes de ser arrestado. La pantalla parlante será G. Yanayev, quien fuera elegido en la tercera ronda, por presión de Gorbachov, al cargo de Vicepresidente de la URSS, careciendo de las debidas cualidades para sustituir al lider. Se anadió al grupo V. Starodubtsev, entusiasta defensor de la colectivización agraria, que en el caso de la URSS demostró la mayor ineficiencia económica y social.

\section{Un golpe desesperado.}

Lo imprevisto del golpe para unos y lo imprevisto del fracaso para los propios golpistas son pruebas de la desesperación acumulada en la troika de los golpistas. En primer lugar, la alta dirigencia o burocracia del partido comunista se venia desprestigiando oficial e históricamente dentro y fuera de la URSS. Historiadores independientes y sobre todo la misma Academia de Ciencias de la URSS habian iniciado, desde 1985, toda una arqueologia histórica desde los pródromos de la revolución de octubre-1917. (ECA, 1991; pp. 675-710). El rechazo del fenómeno estalinista, de sus abusos de poder, de su politica de terror, de sus purgas de los mejores elementos del partido, de los grandes economistas, ingenieros, hombres de la cultura y de unos $\mathbf{4 0}$ mil altos oficiales del ejército... hacen de la "revolución desde arriba" gestada por Estalin una violenta desviación del socialismo democrático. La nueva historia presenta la imagen de Estalin y del estalinismo manchada con toda la gama de crimenes y abuso de poder. Con la crítica a Estalin nace el proceso de rehabilitación de los finados por el Dictador.

Fuera de la URSS, en los foros internacionales ya citados y comentados, el no-mayor a la intolerancia es la crítica al partido único. (Realidad Económica, 1990; pp. 14-43). La crítica al partido comunista no se limita a los crimenes y a la corrupción de dicha nomenklatura, sino que se fundamenta en la contradicción congénita entre socialismo y partido único. Ahi radica la esencia antisocialista de quienes, al monopolizar el todo saber y el todo poder, monopolizaron para si el título de socialistas.

4. El Pais; 25-08-91; p. 7. 
Por ello la crítica,en su riada creciente, ha llegado a sacudir las bases leninistas del partido dominante desde 1971 a nuestros dias. El partido creado para controlar y ejercer todo el poder, dificilmente puede aceptar compartir el poder. Siempre se han resistido a los pasados intentos de hacer perestroika, y nada augura que el golpe de agosto sea el último dentro y fuera de la URSS. Asi lo ha dicho E. Shevardnadze.

Para conservar el poder y para conservarse en el poder el partido hizo simbiosis con la alta dirigencia del ejército y secretó la temida policia de seguridad interna, hoy KGB. Con todo el proceso de desmilitarización interna y con el desmembramiento de la Unión en Repúblicas soberanas, la clase militar quedaba sometida a una dificil transfiguración. Pero hay más razones. El Premio-Nöbel de la Paz 1990, concedido a M. Gorbachov, lo consagraba como el lider en la lucha contra la "mania armamentistica" mundial y como el iniciador del diálogo ("la mano tendida") con el otro sistema. Esto echa por tierra toda la doctrina de la Coexistencia Pacífica, que fundamentaba la paz sobre la amenaza de la guerra atómica: "si quieres la paz, prepara la guerra". La URSS dejaba de ser la potencia temida por sus armas, con peligro de convertirse en una economia mendicante de segunda categoría. La disolución del Pacto de Varsovia, el retiro de las tropas soviéticas de Afghanistan primero, luego del bloque y hoy de Cuba, significaba la jubilación de la alta dirigencia militar. La Perestroika golpeaba en pleno flanco del ejército.

En la misma troika se injerta el complejo industrial bélico-militar, a modo de sector formal y privilegiado con los mejores recursos técnicos, físicos y financieros. Aparte de las dificultades para integrarse en el marco de la producción civil, que sefalara R. Sagdeved, se cuestiona aqui otro aspecto de las contradicciones soviéticas. Tanto en Perestroika como en el informe al Pleno del Partido de 1987, y más recientemente en los programas económicos para la URSS se vuelve una y otra vez sobre las consecuencias recesivas de la inversión extensiva, del rezago tecnológico y de la deteriorada calidad de la producción civil. Parecería que "toda la URSS" ha mantenido un retraso tecnológico. De sobra sabemos que esto no es cierto. Sus adelantos técnicos en el área espacial, en la industrial bélica, en el potencial atómico, en toda la producción militar la convierten en primera potencia y primer exportador de armamento sofisticado. Lo incomprensible y lo que ha sido cada vez más criticado es el muro tecnológico que se levantó entre este sector tecnificado al summun, y el resto de los sectores de la producción civil, industria ligera y agricultura. Es social y económicamente incomprensible y criticable que estos sectores hayan requerido de elevadas importaciones agricolas y de tecnología occidental; que se requieren actualmente (cálculos de G. Yaulinsky) de $\$ 20.000$ a $\$ 30.000$ millones de 
préstamos anuales para la reactivación industrial; que deban cerrarse miles de empresas, dejando seis millones de desempleados para 1992; que haya que convocar la entrada de empresas y empresarios extranjeros, y que haya que enviar a miles de jóvenes soviéticos a aprender la administración de empresas más allá del telón de acero. Realmente, la propiedad pública del Estado (Art. 10 de la Constitución) no fué propiedad del pueblo ni para el pueblo, y por ello no era una propiedad socialista. Por ello el pueblo dejó desde hace tiempo de creer en el partido porque el partido dejó de creer y de servir al pueblo. Se explica asi la valiente reacción del pueblo en la semana trágica de agosto; y se explican las reacciones similares en otras repúblicas y naciones del bloqueEste. Pero, mientras se mantengan las deterioradas condiciones económicas, heredadas del pasado, el golpe sigue siendo una amenaza.

Qué extrañas coincidencias en este contradictorio universo. ¿No han sido las mismas clases de alianzas entre el poder político, económico y militar las que han tipificado la historia latino y centroamericana? - ¿No han generado estas mismas alianzas los descontentos y los levantamientos populares? - ¿No existe hoy el grave peligro de volver a reforzar estas alianzas con los nuevos modelos económicos?. También aqui hablamos de desmilitarización, impunidad, depuración; también hablamos de reconversión industrial, y por supuesto de que el pueblo será el privilegiado de las reformas. No nos rasgemos las vestiduras ante las calamidades socioeconómicas gastadas por el comunismo, porque, sin duda con otra etiqueta, tenemos semejantes retos y problemas. El anecdotario soviético está escrito para nosotros.

\section{Camino de la "economia libre"}

Janos Kornai, destacado economista húngaro, parafraseando la obra de F. Hayek, "the road to serfdom", tituló la versión inglesa de sus propuestas de reforma para Hungria, "the road to e free economy". 5 El título es atractivo, pero el camino hacia una economia libre esta plagado de incertidumbre, especialmente en el caso de la URSS. Ellos enfrentan una sensación semejante a la de una compania de jóvenes paracaidistas que inician su primer salto en el vació sin estar seguros de que vayan a funcionar los paracaidas. La libertad ¿los va a estrellar?; no es más seguro dejarse llevar por el avión? - La verdad es que existen serios intentos y programas alternativos para integrar e integrarse en la economia de mercado. Uno de los problemas más desconcertantes es

5. Andrei Mas-Collell: "El retorno del viaje". En "Reforma económica y crisis en la URSS". Real Academia de Ciencias Morales y Políticas. Ed. t, EspasaCalpe. Madrid, 1991; pp. 114... 
que de la Perestroika para acá la economia soviética ha funcionado "sin plan y sin mercado"6 y no todos están de acuerdo en cómo deba hacerse la transición.

El portavoz del grupo parlamentario Soyuz (unión), el militar Víctor Alksnis, se inspira y elogia el modelo chileno o el de Corea del Sur. "Consideran que sus éxitos actuales se deben a que en su momento el ejército, con mano de hierro, impuso la economia de mercado. Da la impresión de que Alksnis ha decidido poner en marcha lo que Samuelson llama "la solución del diablo" que tiene sus raices ...en las tesis que Schumpeter defendiera más de una vez en círculos privados: "deshagámonos de la democracia e impongamos a la sociedad el régimen de mercado. No importa que tengamos que castrar al sindicalismo y enviar a la carcel 0 al exilio a los molestos intelectuales".' El grupo "Soyuz", segunda fuerza del Congreso ( $25 \%$ de los escaños en 1990), representaría la voluntad de la joven oficialidad". Su proyecto es claro: dictadura con un gobierno de salvación nacional; limitación de las actividades de todos los partidos, incluido el comunista; copia del movimiento japonés en relación con la derrota de 1945: el ejército norteamericano y sus bayonetas han conducido al pais por la via del auge económico, y ése debe saber el papel del ejército soviético; reforma monetaria radical, movilización de toda la población apta para el trabajo, como sucedió durante la llamada "Guerra Patriótica 1941-1945".?... Pero esta via al mercado no seria "road to freedom".

Pareceria que el ejército soviético, inconforme con la política de distensión de M. Gorbachov y del ex-ministro Shevardnadze, intenta recuperar su liderazgo militarizando el proceso de transformación económica. Ante el desprestigio y el desorden del propio partido comunista y el fuego cruzado de los programas económicos alternativos, amén de las protestas callejeras, el ejército se siente llamado a anteponer la disciplina a la democracia. El general Boris Gromov, excomandante de las fuerzas de ocupación de Afganistan, declaraba a La Stampa de Turín, el 27 de diciembre de 1990: "Queriamos un verdadero Estado democrático, pero la democracia no es ni un burdel ni un lugar donde chillan las verduleras. Ni en Tanzania hay tanto desorden como entre nosotros".

Junto con estos grupos militares hay que tomar en cuenta el poder y la posición de la KGB. Para el hoy depuesto presidente V. Kriuchkov, miembro activista del golpe, las suspicacias policiacas recuerdan los tiempos de Yagoda o Beria. "Esto la ha orientado a la persecución de

6. Rojo Luis A.: "la URSS sin plan y sin mercado". Ibidem; pp. 35...

7. Velarde Fuertes Juán: Introducción. Ibidem. pp. 27-28.

8. Ibidem; p. 26 
los "especuladores" y los denominados "ladrones de materias primas". También hacia la vigilancia de la posible conducta antisocial de las empresas de economia mixta con capitales soviéticos y extranjeros. Es evidente que todo esto va contra el espiritu de la Perestroika. No se puede olvidar que en el abandonado Plan de los 500 dias, de E. Shatalin, se recortaba drásticamente los presupuestos de la KGB. Para acabar de entender a Kiutchkov es preciso recordar que es el dirigente que ha verificado unas declaraciones donde sugirió que en los envios de alimentos para aliviar el hambre de la URSS se habian detectado productos radioactivos". ${ }^{9}$

A la aventura reformista iniciada con la Perestroika, aparte de las resistencias del ala conservadora del partido, se agrega el poderoso bloque de la Asociación de Empresas del Estado, que se agregaron al golpe del pasado mes de agosto. Este grupo empresarial presenta su propio programa: "freno a las declaraciones de soberania de las repúblicas separatistas; control centralizado de los precios; transferencia de las propiedades del Estado a colectivos de trabajadores; finalmente, en esta especie de búsqueda de modelo autogestionado a la yugoeslava, abandono de la planificación centralizada". ${ }^{10}$

Estas son algunas de las dispersas posiciones y poderes que han llevado a la deriva la economia de este mosaico de repúblicas, sin plan y sin mercado. Con todo, los problemas de la transición económica son más profundos, cuando se agrega el delicado tema político de la integración de las repúblicas soberanas independientes. Ahora se agregan dos nuevos cuestionamientos. ¿Qué grado de soberania económica implica la independencia de cada república?. Las reformas ¿se van a entender como una transición en continuidad o como una acelerada reestructuración de las variables macroeconómicas y del comportamiento de las empresas? Los programas económicos alternativos difieren precisamente en el modo de enfocar y calanderizar esta doble problemática, arrastrando en su vaivén a $M$. Gorbachov de un extremo al otro de acuerdo a las consecuencias económicas y sociales previsibles en cada opción. El resultado ha sido que el año de 1990 ha sido un ano perdido para las reformas económicas y toda la actividad del Congreso, dominado por los grupos conservadores antes mencionados, se limitó a rechazar los planes alternativos propuestos, los unos por muy radicales y los otros por muy difusos. Se rechazó el Plan de los 500 dias presentado por S. Shatalin, Petrakov, Yaulynsky....; se rechazó la otra alternativa de Abalkin; se calificó de difuso el programa de Rijkov. Se prestó cierta atención

9. Ibidem; p. 28

10. Ibidem; p. 28. 
al programa conciliador de A. Aganbegian (ECA, 1991 pp. 705-708)." Cediendo a las presiones conservadoras, M. Gorbachov presenta al Congreso, en octubre de 1990, el programa titulado "Orientaciones básicas para la estabilización económica y la transición a una economía de mercado", que tampoco ha contentado ni a moros ni cristianos. Al ceder a las presiones del ala conservadora del congreso, lo único que estaba logrando Gorbachov era alargar el período y aumentar los costos de la transición, poniendo en peligro la misma transformación económica. Por anadidura esta involución de la Perestroika le enajenó de sus primeros y más valiosos colaboradores, que uno tras otro renuncian al partido comunista, quedando como testimonio la amarga carta de S. Shatalin, dirigida a las reliquias conservadoras del Congreso. ${ }^{12}$

La ineficiencia del programa-Gorbachov sumado a las presiones que en forma secuencial han venido ejerciendo las repúblicas soberanas por un nuevo Tratado de la Unión, han venido empujando al Presidente de la URSS hacia una posición más aperturista en cuanto a las autonomias republicanas y hacia posturas más radicales en el proceso de transformaciones económicas que explican el precipitado "coup d'Etat" del pasado mes de agosto. Sin embargo, las frustraciones y las dificultades de la reestructuración se venian acumulando, desde 1987, en las cuatro áreas programadas por el mismo Informe de M. Gorbachov al Pleno del Partido. ${ }^{13}$ En la segunda parte de este informe se decía que "el punto de partida de la reforma del sistema de gestión ...la empezaremos desde el eslabón principal de la economía, la empresa y la agrupación".

"Se abandonaba el mecanismo a través del cual la empresa, por medio del sistema de indicadores obligatorios, recibe encargos y recursos. Se eliminan los ministerios sectoriales y la planificación administrativa, y la empresa adquiriría todos sus insumos en el mercado libre al por mayor. Pero ni las empresas se atreven a utilizar estas disponibilidades del mercado, ni el Estado renuncia a controlar por medio del Gossnab el $90 \%$ de las compras directas que suministrará a las empresas. Todavia en mayo de 1990, comenta Marie Lavigne, siguen funcionando 76 ministerios sectoriales de tipo federal y 568 en las repúblicas". ${ }^{14}$ En conse-

11. Aganbegian A.: "La reestructuración de la economia soviética y las relaciones económicas internacionales". Comercio Exterior; mayo-1990, pp. 421424.

12. Velarde Fuertes J. Opus cit. pp. 19-20.

13. Gorbachov M.: "Tareas del Partido en la Reforma Radical de la Administración Económica". Informe al Pleno del PCUS; junio, 1987. Ed. Agencia Novosti. Moscú, 1987. 
cuencia, las empresas que habian deseado integrarse al mercado, vendiendo libremente una elevada proporción de su producción, temian quedarse sin suministros de materias primas e intermedias asi como verse privadas de los correspondientes recursos financieros asignados por los órganos centrales de planificación. Dada la sensible escasez de materias primas era arriesgado confiar en que pudieran adquirirse por un sistema de autofinanciamiento. Por otra parte, en el caso de que la empresa lograse un cierto nivel de beneficios no era posible dedicarlos a inversiones internas, debido en parte a la ausencia de programas de inversión, y sobre todo porque los órganos centrales, siempre deficitarios, absorbian una parte creciente de los excedentes. De hecho, el único destino factible era mejorar los salarios, compensando y alimentando la espiral inflacionista y el problema de la sobreliquidez, dada la penuria de bienes de consumo disponibles en el mercado.

Tampoco funcionó la aprobación legal (noviembre-1986) de la extendida práctica de la "economia subterránea", autorizando las cooperativas familiares 0 individuales en las áreas del comercio, artesanado, reparaciones..., que respondieran a la escasez de todos estos servicios. La razón fué los elevados precios cobrados por los miembros de estas 200.000 cooperativas (1989), que la opinión pública calificaba como "rentas no ganadas, tachando de especuladores a los nuevos cooperativistas. Diriamos que la ley dió autorización a que la puluraran lo que en la década de 1920 se conocia como el "comerciante-NEP", posteriormente castigado. También ahora se ha tratado de controlar a estos antisociales especuladores y a otros grupos acumuladres de ahorros no ganados, imponiendo la obligación de cambiar todos los billetes de 50 y 100 rubros, privándolos de curso legal, por otros billetes de menor denominación, en el plazo de tres dias y hasta el límite de 1.000 rublos por persona. Esta drástica medida, que castigó a culpables e inculpables, ha tenido dos consecuencias; más que frenar la inflación, ello ha servido para que la gente retire sus depósitos de las cajas de ahorro, volviendo a la caja fuerte del calcetín, y que se procure cambiar liquidez por los escasos bienes físicos relativamente costosos. Como de momento no existe un mercado de títulos-valores públicos relativamente rentable, ni tampoco arranca el proceso de privatización-accionariado de las empresas pequeñas o grandes, la única variable resentida ha sido la creciente tasa de inflación.

Otra reforma en la que se habia puesto gran confianza era la liberalización agricola, que hiciera posible un abundante surtido de alimentos a la ciudad. Accidentalmente E. Ligachov, conservador a ultranza y enemigo de Gorbachov (ECA, 1991; pp. 698-699), habia sido removido del Politburó y transferido al puesto de responsable del sector agricola. A 
semejanza de lo sucedido en el sector industrial, las autoridades centrales trataron de acaparar la mayor parte de las compras para hacer frente a los problemas de escasez locales; con lo cual sólo una parte residual podía ser vendida en el mercado a precios más libres. Incluso los dirigentes políticos de las cooperativas disuadian a los campesinos de esta práctica, forzando más bien las ventas estatales para asegurarse el correspondiente suministro de insumos industriales. Pese a que se prometio pagar en divisas a los campesinos no se ha mojorado en nada su nivel de ingresos debido a los retrasos en las liquidaciones. Por otra parte, la escasez de productos agrícolas sigue siendo un problema permanente debido al deficiente servicio de comercialización, deteriorándose aun pudriéndose parte de las cosechas en las instituciones de alma. cenamiento, requeriendo año tras ano de un elevado monto de importaciones alimentarias de los EE.UU. Las dificultades de esta comer. cialización se ha agravado debido al mismo proceso de las independen. cias republicanas, que impone nuevos controles a la transferencia de estos productos de una a otra región. El nacionalismo tiene sus consecuencias de autarquia económica. Esta situación hacía prever que las protestas populares estallarian ya entrado el invierno, con la llegada del frío y la mayor escasez de viveres, lo que sería aprovechado para el golpe de Estado que inesperadamente el ala conservadora y militar adelantaran para el pasado mes de agosto.

Una cuarta área de la reforma económica, que pudiera catalizar la marcha hacia el mercado y el avance tecnológico empresarial, era el programa de las empresas mixtas con capitales soviéticos y extranjeros. Como lo indicaba ya A. Aganbegian en su programa de reformas (ECA, 1991; p. 797), el plan de empresas conjuntas, anteriormente prohibido en la URSS, encontró una serie de recelos y restricciones burocráticas a comenzar por el tema de la repatriación permitida de beneficios. Al estilo chino, se pensó en permitir las zonas francas donde los capitales extranjeros pudieran moverse más libremente. Aunque en 1989 existian 1.300 sociedades mixtas, casi ninguna trabajaba en el sector industrial. Hay indicio de posibles cambios de acuerdo a la nueva apertura de que habla A. Aganbegian: "hoy, un ciudadano extranjero puede ocupar las posiciones directivas más altas de una empresa conjunta y hay mayor libertad para escoger y pagar al personal". Sin embargo, el proceso de inversión extranjera y las empresas conjuntas industriales no pueden desarrollarse mientras no se proceda a la instauración del rublo-convertible, a la reforma de los precios y se simplifique drásticamente "el complejísimo sistema de control de cambios con unos diez mil coeficientes cambiarios que tratan de establecer puentes entre los costes y precios 
nacionales y extranjeros". ${ }^{14}$

No se ha hecho todavia mención de las principales reformas macroeconomicas; la liquidación del enorme deficit fiscal (13\% del PIB) y de la reducción del papel central del Estado como demandante y oferente de insumos; la reforma del sector monetario-bancario, de todo el sistema de precios al por mayor y al por menor, de la liberalización del comercio exterior poniendo fin al monopolio estatal; del proceso de privatización empresarial; de la transferencia de la industria bélico-militar a industria ligera civil; la reconversión de las macroempresas nacidas de la teoria favorable a las mayores escalas de producción..., y todo esto en el contexto del renovado o renovable Tratado de la Unión. Lo hasta aqui dicho pretende mostrar las dificultades existentes en el camino hacia el mercado más libre al nivel inferior de las empresas nacionales, de las empresas conjuntas, de las pequenas cooperativas de servicios y de las tradicionales cooperativas agricolas, kolkhozes. En este marco de recelos y resistencias se han venido debatiendo hasta 1991 los programas alternativos de las reformas, asi como los proyectos de transición de los grupos político-militares antes mencionados. Setenta años de hacer todo lo contrario y de imponerlo doctrinariamente al resto de los paises del bloque no ha sido la mejor escuela de aprendizaje de lo que es y exige una elemental economia de mercado.

El economista espanol Luis Angel Rojo, que ha seguido sobre el terreno este proceso de transformaciones, resume to esencial de estas angustias y temores". Los burócratas desconflan, desde luego, del mercado y temen su expansión; pero esa desconfianza y ese temor lo comparte la mayoría de la población. La capacidad del mercado para ordenar satisfactoriamente las relaciones económicas no es intuitivamente obvia; su entendimiento requiere reflexión y su reconocimiento se basa en una experiencia acumulada. La extensión de los mecanismos del mercado en las economias modernas, frente a las reglamentaciones, los controles y las prohibiciones, fué un proceso lento que hubo de vencer muchas resistencias; $y$ aun consolido, el mercado siempre ha sido objeto de críticas porque su funcionamiento eficaz tiene limites bien conocidos, y siempre contemplado con recelo porque, además de engendrar desigualdades entrana mayores riesgos, menor seguridad y más esfuerzo para todos los sometidos a ella. La aceptación del mercado se fundamenta en una larga experiencia que muestra que, cualesquiera sean los límites y los costos de aquél, las alternativas son, en general, mucho más costosas. La población soviética no tiene, sin embargo, experiencia del mercado como principio dominante de ordenación económica y ha

14. Rojo L.A. Ibidem; p. $41 \ldots$ 
soportado muchas décadas de propaganda adversa; sabe que el sistema de planificación existente funciona muy mal, pero no está segura de cómo se puede pasar a otro sistema mejor y teme que, si falta el plan central, todo se dernumbe; y ha vivido sometida a un orden que desalienta la iniciativa y estimula la inercia, de modo que no hay empresarios que presionen en favor del mercado, en tanto que muchas personas temen que los ajustes previsibles reduzcan sus salarios reales, eliminen sus puestos de trabajo e incluso determinen, como ya ocurrió en el pasado, confiscaciones de sus cuentas de ahorro". ${ }^{15}$

El ano de 1990 fué un año perdido para las reformas económicas, pero no asi el presente ano 1991. Por un lado las crecientes presiones y reclamos de las repúblicas independentistas han ido convenciendo al "Premio de la Paz, 1990" que lo que ganaba fuera lo tenia que practicar dentro; que el proceso de la integración y Unión no se podia lograr por la disciplina militar aplicada en las repúblicas bálticas, sino por la via del diálogo aperturista con que inicia el prólogo de Perestroika. Gorbachov comprende paulatinamente que los programas conservadores, al querer salvar la continuidad, en el fondo protegen un "cambio sin cambio". El mismo distanciamiento de sus más valiosos asesores (Shevardnadze, Yakolev, Shatalin, Petrakov, Grachov, Popov, Sobtchak, Kariakin...) y el enfrentamiento de B. Yeltsin..., le convencen que fué a guarecerse bajo la peor sombra de los conservadores. A lo largo de 1991 se percibe un claro cambio de posición y de posiciones que terminan, con diez dias de diferencia en el frustado golpe de agosto y en la sincera "autocritica de M. Gorbachov". ${ }^{16}$

\section{La autocritica de M. Gorbachov y la crítlca de S. Shatalln.}

A primera vista, tanto el discurso de M. Gorbachov ante el Soviet Supremo el dia 26 de agosto, ya dominado el golpe, como la carta de $\mathrm{S}$. Shatalin (24-8-91), redactada el propio día del golpe y publicada cinco dias después, parecerian dos documentos sin mayor transcendencia dentro del mayúsculo proceso de la reestructuración de la URSS. Creemos, sin embargo, que ambos documentos marcan el nuevo giro que, a raíz del golpe y para evitar un nuevo golpe, tomará la doble reforma política y económica de este mosaico de repúblicas, sumado a las expectativas y condicionamientos de ayuda de parte de los paises occidentales. En el discurso de M. Gorbachov hay, entre otros, un punto transcendental: se convocará de inmediato a elecciones para todos los

15. Rojo L. A. Ibidem; pp. 47-48.

16. "La autocritica de M. Gorbachov: La respuesta a los golpistas fué condescendiente. Me refiero ante todo a mi". El País. 27-8-91; p. 4. 
órganos del Estado, incluida la presidencia de la URSS, que él ocupa. Son cada vez más los comentaristas del proceso soviético convencidos de que las radicales reformas económicas y políticas no pueden llevarse a cabo mas que por un lider nacido de elecciones populares. Esa es hoy dia la diferencia entre Boris Yeltsin y $\mathrm{M}$. Gorbachov; mientras que B. Yeltsin ha sido elegido por aplastante mayoria presidente de la Federación Rusa o República de Rusia, M. Gorbachov es presidente de la URSS por simple elección del ya desacreditado Soviet Supremo. B. Yeltsin ha acumulado y sigue acumulando poderes crecientes para acelerar las reformas internas y para forzar al mismo M. Gorbachov a anular y cambiar los primeros nombramientos que hiciera en estos dias del post-golpe. Por esta razón A. Yakolev ha dicho que "Gorbachov y Yeltsin deben trabajar juntos". Si el ahora más lúcido M. Gorbachov sale electo popularmente Presidente de la URSS tendrá la vía más libre para forzar las reformas.

La carta de S. Shatalin "a mis antiguos camaradas del PCUS", aparte de la dura crítica a quienes frontalmente se habian opuesto a su Plan de los 500 dias, al repetir los mismos juicios de valor que la Academia de Ciencias de la URSS ha publicado desde 1988 en contra del partido comunista soviético, sirve a reactualizar las propuestas del programa económica e integrarlos en el más actualizado proyecto de su colaborador y hoy economista más consultado, Grigory Yaulinsky, asi como en las propuestas del estudio preparado en la Cumbre de Houston, en consultoria con diversas instituciones soviéticas, por el FMI., el Banco Mundial, la OCDE y el Banco Europeo para la Reconstrucción y Fomento ("La Economia de la URRS"). ${ }^{17}$ EI Plan-Shatalin conjugaba la dimensión de la equilibrada integración republicana con la necesaria radicalidad de las reformas económicas, en la dirección que parecen actualmente tomar el tratado de la Unión y los proyectos de reformas. Con cierta exageración se pudiera decir que el golpe de agosto iba dirigido contra la iniciada conversión político-republicana de Gorbachov, y contra la radical reforma económica de Shatalin y su grupo asesor.

El Plan de los 500 dias atribuia un papel protagonista a las repúblicas en la conducción de las reformas económicas y en los puntos básicos de la discusión. Las repúblicas pasaban a ser estados soberanos en puntos neurálgicos como el establecimiento y la recaudación de los impuestos correspondientes y en la forma y monto de su contribución al

17) "The economy of the URRS: summary and recomendations". Washintong, D. C., 1991. Traducción española en: "La Economia de la URSS". Opus cit. (Refoma económica y crisis en la URRS). Real Academia de CC. Morales y Politicas. EDt. Espasa-Calpe. Madrid, 1991; pp. 120-138. 
presupuesto de la Unión. Las repúblicas desarrollarian las políticas más acordes para su desenvolviento económico y desempenarian un papel crucial en el proceso de privatización e integración de una economia de mercado. Las repúblicas tendrian la propiedad y el control exclusivo de la tierra, de los recursos naturales y demás propiedades existentes en el territorio. con ello, a partir de las medidas más abiertas y decididas tomadas a nivel republicano, mejoraria la cooperación entre las repúblics y entre éstas y el poder central. Es claro que este proceso de reestructuración desvalanceaba el esquema inicial de la Unión, los intereses del ala conservadora del partido, asi como la posición centrista de la casta militar y KGB. Inicialmente M. Gorbachov se alineó con estas posturas conservadoras, más por defensa de los principios constitucionales y la integridad de la Unión, que por sus consecuencias económicas. ${ }^{18}$ El viraje realizado en 1991, tanto por las presiones independentistas como por el creciente deterioro económico, fueron acercando a Gorbachov al golpe de estado, en visperas de firmar el Tratado de la Unión. Mirando asi el cambio de coordendas, estos dos breves documento nos sitúan en el entorno político-económico en que se siguen debatiendo las actuales reformas.

\section{- La autocritica de M. Gorbachov}

"Hablo ante todo para mi mismo" dijo M. Gorbachov al abrir la sesión del Soviet Supremo. "El golpe de Estado no surgió de la nada. Lo auspiciaron histéricos articulos de la prensa, el Comité Central del PCUS y discursos de generales en conferencias del partido. En vez de hacerles frente con decisión se hizo gala de liberalismo y condescendencia. Hablo ante todo de mi mismo". Luego del minuto de silencio por los tres jóvenes asesinados, Gorbachov agradeció al Pueblo de la federación Rusa y a su Presidente Boris Yeltsin por su eficaz resistencia a los golpistas. Alabo al "nuevo pueblo", que ha comenzado a autoevaluarse en forma distinta tras décadas de sumisión. "He vuelto a otro pais; el país ya no es el mismo. $Y$ el ejército ya no es el mismo porque es una parte del pueblo "....Gorbachov, que asistió a esta sesión sin la habitual insignia del partido, descalificó el comportamiento del mismo partido y exigió su autodisolución". He incurrido en una grave irresponsabilidad como Presidente por el hecho de que los mecanismos del Soviet Supremo no funcionaron, de que los miembros del gobierno fueron vergonzósamente incapaces y cobardes frente al golpe, y de que a la cabeza de los tres órganos armados hubiera gente capaz de embarcarse en un golpe de Estado". Ante esta coyuntura Gorbachov anadió: "Inmedia-

18. Rojo L.A. Opus cit. pp. 60-61. 
tamente después de la firma del Tratado de la Unión debemos comenzar la campaña para la elección de todos los órganos de la Unión, incluida la Presidencia".

Debido a la intervención y postura de B. Yeltsin, quien considera definitivamente liquida la "Unión Soviética", se entrará "en un proceso de negociaciones sobrias con las repúblicas que no quieran firmar el Tratado de la Unión. Tienen que tener el derecho a una decisión independiente". Renovó sus ataques a los golpistas, añadiendo: "En ningun caso habrá vacilación o demora en el proceso de cambio. No lo toleraré mientras yo sea Presidente". Este párrafo arrancó los aplausos de los congresistas democráticos, mientras que la mayoria reaccionaria guardaba pesado silencio. El ultraconservador militar Victor Alksnis, portavoz de "soyuz", pidió que se permitiera intervenir a los golpistas para que explicaran su actitud: "Existe la presunción de inocencia. Hoy que la situación es tan tensa en nuestra sociedad, debemos saber la verdad". La respuesta fue tajante: "No habrá compromisos con aquellos con los que es imposible e impermisible realizar acuerdos". M. Gorbachov dió a entender que ésta seria la última sesión del Soviet Supremo y que quedaba liquidado el supremo organismo de poder del Estado soviético.

Pasando del legislativo al campo militar, Gorbachov propuso inmediatamente "la suspensión de la legislación que rige las actividades del Comite de Seguridad del Estado, KGB. Hay que crear las barreras infranqueables para que no haya la minima posibilidad de utilizar la KGB para fines anticonstitucionales. Es indispensable elaborar una nueva concepción de la KGB.... Hay que establecer un control social sobre las actividades de las Fuerzas Armadas... La nueva Ley debe especificar el nuevo carácter profesional y despolitizado del ejército rojo"...

Luego de este primer ataque de ablandamiento sobre sus opositores políticos Gorbachov reconoció las dificultades que habia encontrado dentro del "aparato" para llevar adelante las reformas económicas. "Lo primero es que las medidas a.adoptar incluyan la eliminación de todos aquellos obstáculos en la via a la economia de mercado, que plantean las viejas estructuras... Tenemos que acelerar la creación de las estructuras de mercado necesarias". Buscando un fuerte bastión para este proceso Gorbachov anunció la creación de un comité especial para los problemas económicos, presidido por el primer ministro ruso, Ivan Silaiev, y el que integra economistas de notoriedad como la nueva estrella G. Yaulinsky, coautor con S. Shatalin del Plan de los 500 dias y que en el mes de julio habia participado en la cumbre de lo siete grandes. Hay que recordar que Gorbachov rechazó este plan presionado por el ala conservadora; ahora to aceptará de mejor grado, injertando sus li- 
neas generales en las propuestas preparadas por la Cumbre de Houston. Por ello Gorbachov agregó que "será necesario una mayor asistencia económica de los paises occidentales de moneda convertible..., ellos han entendido la necesidad de incrementar esta cooperación". En este contexto y en la dirección que apuntara el Plan Shatalin, Gorbachov evocó la necesidad de otorgar plenos poderes a las repúblicas y limitar la competencia de la Unión en este campo. ${ }^{19}$

En la redacción del discurso se ven dos manos: la de los golpistas que se hieren a si mismos, y la de B. Yeltsin que le cobró a Gorbachov la factura de su eficiente defensa durante los tres dias del golpe. De todas formas, los golpes son parte del sistema de aprendizaje, como dice el refrán: quien tropieza y no cae adelanta camino. Si esta ingrata semana hizo reflexionar a Gorbachov y vuelve a buscar el apoyo de sus primeros y mejores asesores políticos y mejores asesores políticos y económicos podrá controlar las riendas de la imprevisible cuadriga de la integración republicana conjuntamente con la resolución de la reforma macroy microeconómica. $Y$ todo ello en el peor de los momentos: Shevardnadze juzga que la oposición puede intentar un nuevo golpe de fin de ano; y antes de fin de ano llega el crudo invierno ruso a un pais desprovisto de bienes en sus mercados.

Empalmando con el proceso de autocrítica histórica iniciado por la Academia de Ciencias de la URRS desde 1988 (ECA, 1991; pp. 676..) el académico Shatalin escribe el propio dia del golpe una "Carta a mis antiguos camaradas del PCUS", partido al cual renunciara a principios del presente ano. Esta amarga crítica a la historia del partido tuvo amplia publicidad en la URRS a partir del 24 de agosto y ha sido dada a conocer en varios diarios europeos, por la notoria autoridad de su autor. Hay dos razones para trasladar algunos de sus párrafos: recoger su juicio sobre el papel histórico del partido comunista en la URSS, y al mismo tiempo mostrar el tenso entorno en que va a desenvolverse este periodo de transición. No es honesto ocultar la realidad del pasado, de acuerdo a este reconocido académico, ni debemos minusvaluar las dificultades reales de transición a un futuro imprevisible. Si el humor ruso dice: "nuestro pasado es imprevisible", cuánto más lo va a ser el futuro. Sobra decir que no hay ninguna intención de morbosidad académica al trasladar la presente carta, sino la sincera idea de ponderar lo allá sucedido y también lo aqui realizado, bajo otro régimen o sistema. Con esta intención dejo la palabra al académico $\mathrm{S}$. Shatalin.

"Dado que soy partidaria del entendimiento, asi como de la consolidación de todos los movimientos políticos y sociales, de todos los parti-

19. Tomado de "La autocritica de M. Gorbachov". El Pais; 27-8-91; p. 4. 
dos que verdaderamente deseen el bien de nuestro pueblo, he dudado mucho antes de escribir esta carta: ¿no sembraré con ella nuevas semillas de división, discordia, enemistad, irritación y odio?. Sin embargo he llegado a la conclusión de que es mi deber decir toda la verdad acerca del proceso político que está teniendo lugar en nuestro pais... Basándome en las realidades de la vida, en nuestro pais y en otros, he escrito ya -y antes que yo miles de gentes - que la causa fundamental de la enfermedad mortal que aqueja a las sociedades socialistas es la ideologia totalitaria comunista, que ha sido llevada a la práctica de manera especialmente ilustrativa en el primer país del socialismo "triunfante". Para comprender las realidades que estamos viviendo y orientarnos en cuanto a qué hacer, creo que conviene hacer un balance del experimento totalitario comunista... Ese balance es tanto más necesario si tenemos en cuenta que el siglo XX puede ser considerado, sin exagerar, el siglo del comunismo. Asi pues, ¿qué es lo que ha dado el comunismo..., en primer lugar a los habitantes de mi pais?.

1. El atropello de la persona humana, la devastación espiritual y física del género humano, el ataque a la fé, la aniquilación o el ambrutecimiento del alma de las personas.

2. Una política de genocidio masivo contra el propio pueblo. El número de vidas humanas truncadas en la URSS durante los tiempos de paz ha superado el número de victimas de la primera y de la segunda guerra mundial..

3. La creación de una sociedad basada en la hipocresia y la doble moral, compuesta de personas deterioradas y sin principios, fundada completamente en la mentira; una sociedad de denunciantes anónimos y de confidentes, una sociedad en la que cada uno se convierte en el peor enemigo de su propio YO.

4. Una situación catastrófica en cuanto a la economia, la ecologia y la infraestructura. Una economia que, contando con grandes recursos, no es capaz de dar de comer y proporcionar vestido y alimentación a millones de personas que viven en condiciones que ni siquiera alcanzan el nivel de pobreza. Una economía que ha sido supeditada siempre a las ambiciones imperiales, a los intereses del complejo militar industrial. Una economia cuya orientación no ha sido nunca el beneficio de la población.

5. Un ejército que es el mayor del mundo y el menos eficaz; un ejército que no sabe muy bien contra quien se ha preparado para luchar. Un ejército que, pese a la tradición rusa, es obligado a ejercer funciones de gendarme. Un ejército en el que muchos oficiales y generales consideran orgullo el número de conciudadanos "domados" o la cantidad de 
insolencias y denuestos perpetrados contra el Presidente del pais, que es el jefe supremo de las fuerzas armadas....

6. Una cultura y una ciencia en crisis sumidas en desastre total... Cuando el intelecto se hace cada vez más necesario, se ve con malos ojos la investigación de fondo. Minando de raiz el desarrollo de la ciencia y de la ensenanza, el PCUS prepara de manera programada el suicidio del pais sin preocuparse lo más mínimo por las auténticas necesidades del pueblo y del país"....

Dejando su comentario histólico de la revolución de octubre para nuestros dias, S. Shatalin enjuicia las propuestas económicas del PCUS. La economia: "Y qué más nos propone el partido? Me referiré únicamente a la economia. EI PCUS nos propone "el paso a la economia mixta, basada en la diversidad e igualdad de tiversas formas de propiedad: estatal, colectiva y privada, por acciones y cooperativa", indicando seguidamente que la "igualdad" de las diversas formas de propiedad se llevará a cabo dando prioridad a las form: - de prof edad social. No tiene ningun sentido comentar todo este párri' , ciesde un punto de vista profesional y político.... ¿Qué es la propiedaa social?; ¿es estatal?; ¿es cooperativa?, y ¿de quién más?; ¿del PCUS como organismo social?. ¿Acaso no saben los autores del proyecto del proç:ama del PCUS que en todos los paises civilizados la economia es mixta?... Ha transcurrido un año y medio desde el XVIII Congreso del partido, y el PCUS y el gobierno por el dirigido parecen estar haciendo todo lo posible para acabar definitivamente con nuestra ya medio difunta economia...."

"EI PCUS está dispuesto ahora a dar cualquier paso democrático con tal de salvarse y no soltar el poder. Se enmascara, hacen que aumente el miedo, la histeria, sabotea todo lo que 1 l de sabotear, a la vez que, con todo descaro, se presenta a si mismc smo auténtico defensor de los intereses del pueblo. El partido - con su ideologia - que ha llevado de manera premeditada al pais a la enfermedad mortal en que se encuentra, se autoproclama partido de renovación democrática, partido de reformas - y hasta de reformas radicales - a la vez que pretende detentar el monopolio de sacar al país de la crisis económica, social, política, moral y espiritual que padece. El mundo no ha conocido mayor cinismo".

Shatalin comenta a continuación el frustrado intento del Vicepresidente de Rusia, A. V. Rutskoi, de crear el "partido Democrático de los Comunitas de Rusia", que pese a sus mejores intenciones tuvo como resultado aleccionador la expulsión de Rutskoi del pàrtido comunista, adjuntándose al número de los que presentaron su renuncia por propia voluntad antes de que el partido los proyectara. Shatalin sigue comen- 
tando: "Y en cuanto a la expulsión de Rutskoi y Lipinsky del PCUS hay que decir que ese es un método propio de Torquemada, de la inquisición estalinista, y que hay que ser muy ingenuo para asombrarse de ello".

"En mi opinión, es hora de reconocer que en la URRS no existe ya el partido comunista, puesto que ha dejado de ser una iglesia que tienen su base de sustentación en la negación de la propiedad privada, en el colectivismo totalitario y en el fin de la explotación del hombre por el hombre. Si los comunistas reconoceis que vuestro signo distintivo es la negación de la propiedad privada, y por lo tanto de las consecuencias que derivan de ello, decidlo pública y sinceramente. Y si no es asi, decidlo también y renunciad al manifiesto comunista de Marx y Engels. Por ejemplo, B. Stoliarov, presidente del PC de la Federación Rusa, escribe con respecto al partido comunista: "Pierde precisamente porque no quiere convertirse en una fuerza democrática que ayude a la $\mathrm{Pe}$ restroika. Es impensable que el partido comunista tenga porvenir y se salve sin el renacimiento de la traición democrática". Fin de cita de Stoliarov y prosigue Shatalin.: "¿Pero dónde y cuándo habeis visto tradiciones democráticas en el PCUS? ¿Cómo es posible entonces hacer que renazca lo que nunca ha existido?... Yo creo que todas las gentes que tienen por ideologia el sentido común ven con toda claridad que es tan imposible salvar simultáneamente al partido y al pueblo como resolver un sistema de ecuaciones incompatibles... Asi que tenian razón sus colegas, camarada Stoliarov, al regañarle por las equivocadas y atolondradas declaraciones acerca de que el partido comunista podía llegar a ser democrático. Tres miembros del Consejo Presidencial se han ido ya del PCUS. ¿Quién será el próximo?. ¿El presidente de la URRS?. (Nota: en efecto, al día siguiente presentó su renuncia M. Gorbachov) He subrayado en repetidas ocasiones que establezco una frontera clara y precisa entre la ideologia comunista que pone en práctica el PCUS y los comunistas aislados. Aunque he de repetir que la palabra comunista, en cuanto a contenido, hace tiempo que ha perdido todo su valor".

"El pasado año y debido a razones de ideología comunista, los miembros del Soviet Supremo de la URSS, que defienden incansablemente los intereses del pueblo trabajador, nos impidieron pasar en 500 dias a la economia de mercado. A la economia de "mercado" de los 500 dias prefirieron la terapia "planificada" de superchoque del Gabinete-Paulov, que habria que calificar de asalto a mano armada y que no tiene el menor sentido. Pero los comunistas son gente bondadosa. Estan acostumbrados a perdonarse a si mismo los errores; lo importante es que estos errores no entren en contradicción con las reglas del bizantino juego político. Porque lo de la defensa del pueblo es un buen asun- 
to. Aunque para los idealista, y no para los materialistas que tienen sus propios intereses materiales. $Y$ a eso queda reducido todo el materialismo dialectico y también el histórico".

"¿Qué es lo que sucede entonces? ¿No tiene el PCUS ninguna posibilidad de ayudar al pueblo a renacer poco a poco a una vida humana normal? -EI PCUS ya ha cumplido de sobra su misión histórica; ha mostrado a todo el mundo y a su propio pueblo de qué manera resulta imposible vivir. Aunque el precio pagado por esa afición irresponsable a hacer proyectos sociales irrealizables, impuestos a la gente, ha resultado desde el punto de vista histórico, enormemente alto, cruel y sangriento. Es un axioma, a la vez que un teorema demostrado, que el PCUS no puede cambiar. Su única y última oportunidad histórica reside en que reconozca su culpa ante el pueblo y abandone la arena política. Por eso me dirijo a mis camaradas del PCUS para decirles: convertíos en comadrona de la historia. Pero, por favor, sin violencia ni revoluciones". ${ }^{20}$

La carta de S. Shatalin no es un documento aislado, nacido de la ira acumulada el propio día del golpe comunista; es uno de los muchos documentos emanados luego de que la ctual Academia de Ciencias del URRS iniciara todo el proceso de revisión y recuperación histórica rusa y soviética, ${ }^{21}$ toda una obra de arqueología histórica realizada por los mejores historiadores, sociólogos, ${ }^{22}$ economistas, políticos.... (ECA; 1991 ; pp. $679 . .$.$) Una vez descancelados los Archivos Históricos, la bio-$ grafia, de Roy Medvedev sobre la ascensión, conformación del "socialismo desde arriba" y control dictatorial del PCUS por Estalin, ${ }^{23}$ la historiografia soviética suma novecientas páginas más a los crueles hechos referidos en la carta de Shatalin. La glasnot se ha hecho escuchar también en los foros internacionales, dentro y fuera de la URRS: Foro de Barcelona (1988), junto con la "mesa redonda" de Moscú (1988); Foro de Moscú (1989); Foro de la Sorbona, París (1990), acompanado de la macroencuesta europea (1990) ${ }^{24}$ Como lo estamos presenciando en los últimos meses, el proceso de desestalinización y de rehabilitación de los miles de purgados está subiendo rio-arriba hasta derribar la misma

20. Shatalin S.: La última oportunidad". El Pais; 5-9-91; pp. 4-5.

21. Academia de CC. de la URRS. "Problemas Centrales de la Historia: nuevos estudios y enfoques. Edt. Nauka; Moscú, 1990.

22. Academia de CC. de la URRS: "La sociología soviética en la Perestroika". Edit. Nauka. Moscú, 1990.

23. Medvédev R.: "Let history jugde: the origins and consecuencies of Stalinism". N. Y. Columbia Press U. 1989.

24. Ibisate Fco. J.: "Hacia dónde va el Este y hacia dónde va el Oeste? Realidad Económico-Social. Enero-febrero, 1990. pp. 9-44. 
efigie de Lenin, creador del partido único. La diversidad de movimientos socialistas europeas estan, en los foros y encuentros mencionados, devolviendo al PCUS el boomerang que éste les lanzara en la década de los 1920; para el PCUS el resto de movimientos socialistas o sindicalistas, que no se adhieran al partido y modelo soviético, eran los "socialtraidores". Ahora los acusadores son los acusados y ello plantea toda una revisión histórica sobre el verdadero socialismo. La historia del PCUS ha servido, por lo menos, para comprender "lo que no es socialismo". Sin embargo han hecho un gran daño a la imagen y al contenido del socialismo, porque al apropiarse y monopolizar ellos la palabra de socialismo to han desacreditado internacionalmente y han dado lugar a un sindrome de superioridad del capitalismo, sobre base de que hay que escoger entre los dos extremos de dos regimenes históricamente semejantes en su efectos. La confusión de terminologia ha llegado a tal extremo que, al decir del economista Grachov (Congresista del grupo Unión Democrática), estemos hoy llamando "socialismos reales" a quienes montaron un "socialismo irreal o más que real, ya que albergaba la ambición de estar por encima de la realidad y del realismo". ${ }^{25}$

\section{La economla de la URSS: dlagnóstico y recomendaclones}

Por algun lado tiene que romperse el círculo vicioso político-económico. No hay salida económica posible sin una posible unidad política; y no hay una posible unidad política sin la posible solución económica. La peor solución sería la plena desintegración como respuesta aislacionista a los setenta años de forzada centralización. Los dos problemas se debaten al unisono: el Tratado de la Unión y los Programas alternativos de las Reformas Económicas. La conflictividad crece no sólo porque el Tratado y los Programas tienen adversarios, sino porque ambos presentan alternativas diferentes; con lo cual se multiplican los opositores a los esperados resutados de las diversas alternativas. El pasado centralismo ha generado el nacionalismo, el espiritu de aislamiento, autarquia, incluso el virus de la xenofobia. Por ello, S. Shatalin ha dicho: "la Unión Soviética será un pais basado sobre los principios de la unidad económica".

Por lo que toca a las mismas reformas económicas, el problema de la perestroika, entendida corno "revolución", no está sólo en que hay que gestionar toda la economia con un giro de 180 grados, sino también en que nunca se ha tenido la experiencia sino de un modo distinto de administración económica. Muy bien nos describio L.A. Rojo las dudas y

25. Ibidem: pp. $34 \ldots$ 
vacilaciones ante la entrada en una economía de mercado, que la ensenanza oficial presentaba como meterse en la jaula del león. Sin duda, las reformas económicas exigen mayor reconversión, mayores sacrificios y mayor colaboración de todos los gnupos sociales. Pero, ¿qué es lo que puede motivar la reconversión, los sacrificios y la mayor colaboración? - Hay un factor histórico que puede catalizar todo el proceso: el mismo derrumbe y deterioro económico, que el humor ruso comenta: "nuestro pasado es imprevisible". Se ha llegado a lo imprevible y hay que buscarle una salida.

Las autoridades soviéticas y la academia de Ciencias de la URSS han proporcionado todos los datos requeridos para que el Banco Mundial preparara el ya citado informe sobre "La economia de la URSS: diagnóstico y recomendaciones" (1991). El pasado mes de julio M. Gorbachov se hizo presente en la reunión Cumbre de los siete para solicitar la mayor ayuda de Occidete. La glasnot expuso toda la verdad económica.

Como lo indica Gorbachov en el capítulo primero de Perestroika (pp. 16-20) el Producto Nacional mostraba un serio declive desde la década de los setenta (era del estancamiento-Bresnev), declive tanto más grave porque se mantenian tasas crecientes de inversión. De acuerdo a la metodologia de contabilidad nacional soviética, el Producto Material Neto (no incluye servicios) presenta las siguientes tasas de crecimiento por décadas y quinquenios:

$\begin{array}{ccccc}1951-1960 & 1961-1970 & 1971-1980 & 1981-1985 & 1986-1990 \\ 17 \% & 9 \% & 7 \% & 4 \% & 1 \%\end{array}$

Los datos toman en cuenta, obviamente, el gran crecimiento de la industria bélico-militar. En las series se aprecia claramente el frenazo desconcertante en la postperestroika.

A partir de 1985 se quiere rehabilitar el crecimiento con la campana de "la reforma del sistema económico", anteriormente comentado. Datos oficiales revelan el crecimiento del Producto Material Neto (Net Material Product, N.M.P. en el informe del Banco Mundial) 
N.M.P.

Industria

Agricultura

Construcción

Transporte y

Comunicaciones

Consumo privado

Inversión neta

$\begin{array}{rr}4,3 & 3,2 \\ 5,1 & 3,9 \\ -0,2 & 1,0 \\ 3,1 & 3,2\end{array}$

$\begin{array}{rrrrrrrr}3,8 & 2,9 & 0,8 & 4,2 & 0,3 & 5,8 & -6,5 & - \\ 4,2 & 2,9 & 3,4 & 1,9 & 2,7 & 3,9 & 5,3 & 3,0 \\ 2,6 & -1,7 & -1,1 & 4,9 & 5,7 & -7,4 & -6,7 & -20,0\end{array}$

Fuente: Autoridades Soviéticas. Informe Banco-Mundial; p. 4.

Considerando que no se toma encuenta la inflación real subyacente (los datos oficiales no la incluyen) tendriamos una tasa de crecimiento negativa, valuada a precios constantes. En esta contracción influyó fuertemente la caída de los precios del petróleo, rubro importante de sus exportaciones, lo que obligó a incrementar las exportaciones a paises de moneda convertible y a reducir las importaciones. La contracción general y la pérdida de valor de las exportaciones generó un deterioro secuencial del deficit fiscal, que pasó de un 2,5\% del PIB, 1985, aun $8,7 \%$ en 1987. A. Aganbegian, en su programa de reformas, to eleva hasta un $13 \%$. En concordancia con el deficit fiscal se da un acelerado crecimiento del flujo monetario, que en parte pasa a los depósitos bancarios de las empresas subvencionadas y en parte a los depósitos de las familias gratificadas con salarios compensatorios. El problema de la sobreliquidez se muestra en el incremento anual del M2, que pasa del $8 \%$ en 1988 al $16 \%$ en 1990 , asi como de los ingresos familiares que aumentan de $4 \%$ en 1986 al $15 \%$ en 1990 .

En 1987 se emite la Ley de la Reforma de las Empresas Estatales. Sin embargo, pocas empresas inician el proceso de contratos horizontales entre unidades de producción, con administración autónoma de sus propios fondos para inversiones internas; y el único efecto sensible serán las mejoras salariales. Por su parte el Gosnab (órgano estatal de los suministros) sigue cartelizando el $90 \%$ de los insumos empresariales. La novedad y los recelos frente a la reforma esterilizan su posible éxito. Otro rubro de la reforma fué la liberalización del comercio exterior, junto con una simplificación y readecuación del sistema de múltiples cambios. Pero al aplicarse esta reforma de manera fragmentaria el efecto principal fué un fuerte crecimiento de las importaciones de países con moneda convertible, y una insensible variación de las exportaciones manufacturadas: 


\begin{tabular}{lccrrrr}
\hline \multicolumn{1}{c}{ Comercio exterior } & $1986-89$ & 1986 & 1987 & 1988 & 1989 \\
\hline Volumen Exportac. & $\%$ & 4,5 & 10,0 & 3,3 & 4,8 & - \\
Con el CAEM & $\%$ & 1,7 & 3,9 & 0,9 & - & 1,9 \\
Otros paises & $\%$ & 6,5 & 15,5 & 6,0 & 6,3 & $-1,0$ \\
Volumen Importac. & $\%$ & 1,3 & $-6,0$ & $-1,6$ & 4,0 & 9,3 \\
del CAEM & $\%$ & 1,0 & 0,7 & 1,5 & - & 2,0 \\
de otros palses & $\%$ & 1,8 & $-14,3$ & $-2,0$ & 8,6 & 18,5 \\
$\quad$ Variación de & & & & & & \\
términos de intercam. & $\%$ & $-5,2$ & $-10,5$ & $-2,0$ & $-9,0$ & 1,1 \\
Con el CAEM & $\%$ & $-3,7$ & 1,9 & $-5,6$ & $-6,3$ & $-4,5$ \\
Con otros paises & $\%$ & $-6,4$ & $-22,4$ & 7,8 & $-11,2$ & 3,3 \\
\hline
\end{tabular}

URSS: Deuda externa y reservas.

(En miles de millones de dólares)

\begin{tabular}{|c|c|c|c|c|c|c|}
\hline Años & 1985 & 1986 & 1987 & 1988 & 1989 & 1990 \\
\hline $\begin{array}{l}\text { Deuda Externa } \\
\text { a corto plazo } \\
\text { Servicio-Deuda como } \\
\% \text { de exportaciones } \\
\text { reservas de divisas }\end{array}$ & $\begin{array}{l}28,8 \\
6,9 \\
(-) \\
12,9\end{array}$ & $\begin{array}{r}31,4 \\
7,4 \\
(27,7) \\
14,7\end{array}$ & $\begin{array}{r}39,2 \\
8,6 \\
(26,5) \\
14,1\end{array}$ & $\begin{array}{r}43,0 \\
11,2 \\
\\
(23,1) \\
15,3\end{array}$ & $\begin{array}{r}54,0 \\
17,7 \\
\\
(24,2) \\
14,7\end{array}$ & $\begin{array}{r}52,2 \\
10,0 \\
(33,0) \\
5,1\end{array}$ \\
\hline
\end{tabular}

Fuente: Autoridades Soviéticas y BIS. Informe Banco-Mundial; p. 50.

Aunque en 1987 se realiza una profunda reforma del sistema bancario, estableciéndose unas 100 instituciones especializadas, sin embargo el Gosbank no dispone de la independencia ni de los mecanismos para combatir la inflación. Las tasas de interés, pasivas y activas siguen siendo negativas, incrementándose la sobreliquidez empresarial a costa del deficit en el erario estatal. Semejante falta de disciplina se aprecia en la fijación de los salarios sin que hayan tenido éxito alguno los intentos por taxar estos desmesurados ingresos. Aunque las empresas gocen de una mayor autonomia de gestión ellas se enfrentan con un sistema de precios rígidos y distorsionados que prácticamente imposibilita una verdadera autogestión financiera. El deficit empresarial y, en consecuencia, el deficit estatal siguen financiados en forma casi exclusiva por el Gosbank. Pese a cierta reducción del crédito a las empresas la emisión monetaria crece a un ritmo del $14-15 \%$ anual entre 1987 y 1990. Con ello las empresas acumulan inventarios ociosos o se embarcan en proyectos que no pasan de ser construcciones inacabadas.

Los desequilibrios internos, sumados al deterioro del tipo de cambio 
externo, se traducen en una persistente debilitación de la balanza de pagos. Debido a la persistente caida de los precios del petróleo desde 1986 y a que los precios del segundo semestre de 1990 habian sido contractualmente fijados a inicios de ano, la balanza comercial con los paises del CAEM se presenta deficitaria. El superavit comercial con los paises de moneda convertible desaparece rápidamente, elevándose la deuda externa a más de $\$ 60.000$ millones, según últimos datos, con un elevado porcentaje de deuda de corto plazo.

Se han dado serias contracciones en la producción de carbón y petróleo; ello se debe, en parte a las huelgas mineras y a los descontentos laborales, porque las regiones productoras de estas importantes materias primas no han recibido por anos la correspondiente atención del Gobierno Central en proyectos de vivienda, saneamiento ambiental y otras necesidades socio-familiares. Por otra parte, se impone toda una reconversión del equipo extractor relativamente obsoleto. A todo ello se ha anadido otro importante cuello de botella: la declinante y oscilante producción agraria y de los deficientes servicios del transporte. En este punto, toda la efervescencia nacional (problemas étnicos y nos sólo republicanos) multiplican los problemas de almacenamiento y de distribución interregional. Un nuevo factor ha hecho su aparición: la oposición a la presencia de algunas industrias básicas por sus deseconomias ecológicas. Asi se han multiplicado las presiones por cerrar ciertas plantas o impedir la apertura de otras nuevas a raiz del desdichado desastre de Chernobil. Al igual que en Alemania del Este, la contaminación ambiental es un serio problema en amplias zonas industriales, que explican las mencionadas protestas de los trabajadores.

Sea una consecuencia o sea un objetivo buscado por las mismas reformas también ha declinado la inversión de capital desde un $14 \%$ del N.M.P., en 1988, aun $11 \%$ en 1990 . Simultáneamente se percibe un descenso en el volumen de la fuerza de trabajo, hecho explicable por la reducción de la población en edad de trabajo; se suma el problema del envejecimiento de la población; lo que supone una nueva carga de la seguridad social. Sin embargo, el problema más serio del desempleo se presenta por el necesario cierre tecnológico de cientos y quizás miles de empresas. Se calcula (datos de Yaulinski) que todo este proceso de readaptación pueda generar unos seis millones de desempleados para 1992, conjugándose los problemas de readaptación profesional y de crecientes subvenciones a cargo del erario estatal.

Punto y aparte es la elevada proporción de la industria bélico-militar dentro de la economia. El tema es debatido muy ardientemente y se hacen los mejores intentos por su reducción y transferencia a la industria ligera de uso civil. También en la URSS el secreto militar trata de 
ocultar sus elevados gastos presupuestarios, que tanto analistas internos como de las Naciones Unidas los elevan al $18 \%$ del PTB. Las exportaciones de armamento pueden estimarse en unos \$16 018 millones, lo que representa el $15 \%$ de las exportaciones. Es claro que la concentración de los mejores recursos y mano de obra más calificada en la producción bélico-militar se convierte en un obstáculo para mejorar la productividad de la manufactura civil, amén de las resistencias militares y para militares a la deseada reducción y transferencia de este sec-; tor siempre privilegiado.

Con todos estos antecedentes, los problemas económicos crecen a todo lo largo de 1990. Oficialmente se calcula una reducción del $4 \%$ en el Producto Material Neto, por contracción -sobre todo- de la industria, la construcción y el transporte, sin que las mejores cosechas de 1990 se hayan dejado sentir en el conjunto del pais, por las razones ya mencionadas. Se espera que los beneficios de las empresas bajen en un $10 \%$ en 1990 , aunque el sector de los servicios haya crecido en un $2 \%$. El aumento más sensible se ha dado en la partida de sueldos y salarios, un $12 \%$, incrementándose los ingresos familiares aun en mayor proporción. Al mismo tiempo, como se anotó antes, se percibe una declinación del empleo total, más la aparición del fenómeno, oficialmente no censado o no admitido anteriormente, el desempleo.

Pese a los esfuerzos por aplicar nuevas medidas fiscales, la cobertura del presupuesto estatal es la causa principal de la emisión de moneda. De momento no han tenido efecto sensible la emisión de obligaciones o rentas de estado entre el público no bancario. La emisión de moneda mantiene un ritmo rápido al renovar el crédito a las empresas. Con ello la inflación abierta y la inflación reprimida siguen creciendo; los datos oficiales estiman en un $5 \%$ la inflación de precios al por menor, y la inflación reprimida (precios administrados) en un $12 \%$. Se estima que el monto de la sobreliquidez alcanza los 250 mil millones de rublos; dos terceras partes en poder de las familias, como dinero liquido o bajo forma de depósitos. Esto ha venido presionando la demanda de importaciones de bienes de consumo, dada la carestia interna; el consumo interno creció sólo un 3\%.

La Academia de Ciencias de la URSS ha publicado dos cuadros que respectivamente nos describen la distribución de la población por renta y por ahorro, asi como la distribución de los depósitos en las cajas de ahorro. El primer cuadro serviria a construir una "curva de Lorenz" de la población soviética en 1990, y apreciar que dentro de la URSS se presentan también amplias zonas de pobreza asi como una abierta discriminación de ingresos monetarios. Por otra parte, dado que en 1990 
Distribución de la población por renta y ahorro (enero-1990)

\begin{tabular}{|c|c|c|c|c|c|c|c|}
\hline $\begin{array}{l}\text { Nivel-renta-mensual } \\
\text { (nublos per-capita) }\end{array}$ & $\begin{array}{l}\text { Total grupo } \\
\text { (millon. perso.) }\end{array}$ & $\begin{array}{l}\text { Renta anual } \\
\text { per capita }\end{array}$ & $\begin{array}{l}\text { Renta total } \\
\text { (bill. rublos) }\end{array}$ & Ahorros & $\begin{array}{l}\text { Total ahorros } \\
\text { per capita }\end{array}$ & $\begin{array}{l}\text { Total ahorros } \\
\text { grupo-renta }\end{array}$ & $\begin{array}{l}\% \text { total } \\
\text { ahorros }\end{array}$ \\
\hline Menos de $50 \mathrm{R}$. & 8.3 & 300 & 2.5 & 0 & 0 & 0 & 0 \\
\hline 50-75 R. & 27.7 & 810 & 29.2 & 0 & 0 & 0 & 0 \\
\hline 75-100 R. & 44.7 & 1.050 & 56.9 & 0 & 0 & 0 & 0 \\
\hline 100-125 R. & 50.2 & 1.350 & 67.8 & 0.1 & 135 & 6.8 & 1.5 \\
\hline 125-150 R. & 44.9 & 1.650 & 74.1 & 0,2 & 330 & 14.8 & 3.4 \\
\hline 150-175 R. & 35.0 & 2.010 & 70.4 & 0.3 & 585 & 21.1 & 4.8 \\
\hline 175-200 R. & 25.7 & 2.250 & 57.8 & 0.4 & 900 & 23.1 & 5.3 \\
\hline 200-250 R. & 28.8 & 2.700 & 77.8 & 0.6 & 1.600 & 46.7 & 10.8 \\
\hline 250-300 R. & 9.2 & 3.300 & 30.4 & 0.8 & 2.640 & 24.3 & 5.3 \\
\hline 300-350 R. & 4.0 & 3.900 & 15.6 & 1.2 & 4.680 & 18.7 & 4.3 \\
\hline 350-400 R. & 3.0 & 4.500 & 13.5 & 1.7 & 7.650 & 23.0 & 5.2 \\
\hline $400-450 \mathrm{R}$ & 2.0 & 5.400 & 10.8 & 2.2 & 11.880 & 23.8 & 5.4 \\
\hline Más de 500 R. & 2.0 & 31.600 & 63.2 & 3.8 & 118.850 & 237.7 & 53.8 \\
\hline Total & 285.5 & 1.961 & 560.0 & 0.0 & 1.541 & 440.0 & $100 \%$ \\
\hline
\end{tabular}

Fuente: Academia de Ciencias de la URSS

\section{Depositos en cajas de ahorros}

\begin{tabular}{l|ccc}
\hline $\begin{array}{l}\text { Tamaño de los } \\
\text { depósitos-ahorro }\end{array}$ & Ne de cuentas & $\begin{array}{c}\text { Media del total } \\
\text { por cuentas (rublos) }\end{array}$ & $\begin{array}{c}\text { Total } \\
\text { (billones-rublos) }\end{array}$ \\
\hline Menos de 300 R. & 65.378 & 113 & 17.4 \\
300-1.000 R. & 44.801 & 642 & 28.8 \\
$1.000-2.500$ R. & 48.161 & 1.562 & 75.2 \\
$2.500-5.000$ R. & 24.320 & 33.385 & 82.3 \\
$5.000-10.000$ R. & 11.138 & 6.563 & 72.8 \\
$10.000-25.000$ R. & 2.155 & 13.155 & 28.3 \\
$25.000-50.000$ R. & 51 & 31.947 & 1.6 \\
Más de 50.000 R. & 3 & 72.967 & 0.2 \\
Total & 106.007 & 1.614 & 207.0 \\
\hline
\end{tabular}

Fuente: Academia de Ciencias de la URSS. (Tomado de El País. 25-agosto 1991; p. 28)

Digitalizado por Biblioteca "P. Florentino Idoate, S.J."

Universidad Centroamericana José Simeón Cañas 
hubo una reconversión o mejor una requisición de billetes de 50 y 100 rublos, sin duda buena parte de estos depósitos han escapado del sistema bancario y de las cajas de ahorro. "Rublos hasta en el calcetín: sólo una décima parte del ahorro familiar en la URSS se deposita en las cajas de ahorro".

Aunque el presente comentario se centra en el macrodiagnóstico y en la orientación de las reformas económicas, no se puede silenciar de paso el escándalo y disparidad social que manifiestan estos dos cuadros editados por la Academia de Ciencias de la URSS. Tanto S. Shatalin, en carta al partido, como A. Aganbegian en la introducción a su programa de reformas (ECA, 1991; p. 705) destacan el problema de la extendida pobreza en amplios lugares y sectores de la multinacional-URSS. EI mejor comentario y el más breve lo hace M. Gorbachov en su Perestroika. "En ciertos niveles administrativos surgió un desacato a la ley y se fomento la adulación y el soborno, el servilismo y la glorificacion. La gente trabajadora estaba justamente indignada ante el abuso de poder, la supresión de la crítica, las fortunas mal habidas, y en algunos casos incluso, se hizo cómplice o fué organizadora de actos criminales". (p. 22) Sobra este comentario para entender otra causal de las resistencias conservadoras. Las derechas son derechas en todas partes.

Continuando con el diagnóstico de 1990, se percibe un descenso en las exportaciones dirigidas al CAEM, mientras que se eleva el deficit comercial con los paises de moneda convertible. Pese a la exportación y venta de oro por $\$ 4.000$ millones, la balanza de capital presenta un deficit de $\$ 7.000$ millones, debido a la reducción del crédito a corto plazo. El acceso al mercado de capitales sólo es factible con la garantia del gobierno acreedor. El deficit global de la balanza de pagos, $\$ 14.000$ millones, se ha financiado con una brusca contracción de las reservas en monedas convertibles, más la acumulación de moratorias con diversos paises acreedores. Esto pone a la URSS en una difícil situación para obtener nuevos préstamos. De ahi la necesidad de la "mano-tendida" por M. Gorbachov en la reunión Cumbre de los siete de julio 1991.

Aunque el tradicional sistema de planificación centralizada no funciona, tampoco ha sido reemplazado por un mecanismo orientador de mercado. Si bien todo esto afecta al conjunto de la economia, se hace más visible en el comercio al por menor, donde crece la penuria de bienes domésticos, se practica el trueque (los cigarrillos vuelven a ser moneda) y sobre todo impera el mercado negro. El proceso de autonomia de las repúblicas agrava el problema de los suministros interregionales, promueve el sistema de trueque junto con la migración poblacional. El desconcierto económico parecerian dar luz-verde a los lineamientos presen- 
tados por M. Gorbachov "para la estabilización de la economia y la transición a la economia de mercado". El programa presentaba asi la situación: "La situación de la economia continúa deteriorándose. El mercado de consumo está en la peor situación. El deficit presupuesto y la solvencia gubernamental alcazan niveles críticos. Prolifera la conducta antisocial y los crimenes. El pueblo encuentra cada vez más difícil la vida y pierde su interés por el trabajo y su fé en el futuro. La economía se halla en un verdadero peligro. El antiguo sistema de gestón administrativa ha sido desmantelado, pero el impetu para trabajar bajo un régimen de mercado. Debemos tomar medidas enérgicas, con el consentimiento popular, para estabilizar la situación y acelerar el progreso hacia la economia de mercado". ${ }^{26}$

Los lineamientos no muy precisos del programa, la reformulación de la integración republicana promovida por los movimientos separatistas, la contrainsurgencia de los proyectos militares y paramilitares, la pérdida de credibilidad presidencial, $M$. Gorbachov, por parte del ala conservadora y el distanciamiento de sus más valiosos asesores, sumado todo ello al miedo por lo desconocido, desembocaron en el esperado y desesperado golpe de estado de agosto-1991. El fallido golpe puede aliviar al presente los fallidos intentos de reestructuración del pasado. Tanto más que la situación económica se ha ido agravando en el primer semestre de 1991; es de esperar que el resorte oprimido fuerce un salto hacia una mejor dirección. Vuelven a ponerse sobre el tapete alternativas de L. Abalkin y de S. Shatalin. Sin duda al Plan de los 500 dias de Shatalin es más afín al nuevo Tratado de la Unión en proceso. Sobre todo que el programa que goza de mayor prestigio interno y mayor apoyo internacional es el preparado por $\mathrm{G}$. Yaulinski con asesoria externa, incluidos técnicos de Harvard y es considerado como una réplica del plan-polaco y de su asesor J. Sachs. Yaulinsky asistió a la Cumbre-7 de julio 1991.

Sucede que el deterioro económico de la URSS no sólo ha llegado a un punto crítico en 1991, sino que viene impactado severamente a los antiguos satélites del bloque. De acuerdo a cálculos de G. Yaulinski, la producción ha decaido en un $10-12 \%$ (hasta un $25 \%$ en ciertos sectores) en lo que va del año; la inflación crece de tres a cuatro puntos semanales; el abastecimiento alimentario es deficiente e imprevisible. Shevardnadze habla de una situación crítica, y el primer ministro encargado de constituir el consejo económico asesor, Silayev, ha solicitado una masiva ayuda alimentaria a la comisión europea: 5,5 millones de

26. "The economy of the URSS". p. 10. Los datos anteriores han sido extractados de este informe: pp. 1-10. 
toneladas de trigo; 900.000 toneladas de azúcar; 800.000 de carne y cantidades inferiores de otros 15 productos. Es lo que en Brusela se ha llamado "la carta de los $\$ 5.000$ millones". Yaulinski: "no podemos pedir nada, mientras no haya un acuerdo económico interrepublicano". Los dos problemas van del brazo. ${ }^{27}$

Pero también van del brazo los problemas de la URSS y los de sus antiguos aliados, planificados para servir y depender de la URSS. Al reducir la URSS en un $45 \%$ sus importaciones en 1991, no puede menos de afectar las exportaciones de sus antiguos aliados y tradicionales abastecedores. El Ministro de Economia y Desarrollo de Polonia (el pais de bloque con mayor deuda externa) sefáló que las exportaciones de su país a la URSS habia caido en un $68 \%$ en el primer semestre del año. "El resurgir del comercio depende enteramente del éxito de la transición en la URSS, aunque confió en que en diez años las relaciones se normalicen con una diferencia: no serán el resultado de una planificación centralizada, sino que responderán a unos intereses económicos". La transición comercial se impone, en forma difícil, a estos satélites que pivoteaban en torno a la URSS. No les resulta sencillo volverse hacia Occidente, estando en semejante situación Hungria, que también ha visto descender en un $\mathbf{5 0} \%$ sus exportaciones a la URSS. Polonia, Hungria y Checoeslovaquia solicitan una mayor apertura de la Comunidad Europea para que "con 20 años de diferencia" puedan repetir la hazana de los tigres o dragones surasiáticos. En resumen, la especialización planificada desde Moscú sigue obstaculizando el ingreso de estos serviciales aliados en el régimen del mercado occidental, que por anadidura les traba con el proteccionismo en algunas ramas donde aquellos paises tienen ventajas comparativas: producción agricola, textil, metalurgia, quimica..." 28

"100.000 millones de dólares para la URSS. Esta es la cantidad que desearia recibir de la Comunidad Occidental para la URSS. Luego de la Cumbre de los siete (EE.UU. Alemania, Japón, Francia, Reino Unido, Italia y Canadá), con la sesoria de los académicos J. Shachs de Harvard, S. Ficher del Banco Mundial y G. Yaulinski, se han definido las condiciones bajo las cuales la URSS pudiera recibir la ayuda de $\$ 100.000$ millones en los cinco primeros años. Se ha tratado de presentar este proyecto como "el gran negocio" (the grand bargain) El objetivo es aliviar las dificultades de la transición, porque el colapso económico

27. "Gorbachov y las repúblicas debatirán el Plan-Yaulinski. El País; 15, septiembre, 1991; p. 2.

28. "La URSS ha reducido un $45 \%$ sus importaciones en 1991". El Pais; 25 , agosto, 1991 ; p. 28. 
de la URSS y el malestar de su población tendrian consecuencias muy negativas para Occidente. Esta ayuda sería inferior, en términos de percapita, a la ayuda ya prestada al resto de paises del Este; seria menor a la cantidad otorgada por los EE.UU. bajo el Plan Marshall, que en dólares de hoy alcanzó, según Sachs, los $\$ 300.000$ millones. Además el monto de esta ayuda "es muy inferior al gasto anual en que incurre EE.UU. con el fin de disuadir cualquier amenaza de invasión soviética a Europa".

Una forma de conocer la reformas económicas a realizar en la URRS es repasar los condicionamientos de la ayuda solicitada. Ya se ha cumplido la primera premisa: no se suministraria ninguna ayuda mientras el FMI y el Banco Mundial no terminen su estudio sobre "la Economia de la URSS", de manera que las evaluaciones se apoyen sobre datos estadisticos. Se entenderá por qué las autoridades soviéticas han abierto sus reportes estadisticos, utilizados en el presente comentario. Una precondición para iniciar la ayuda es la reducción de la inflación "mediante el recorte de los subsidios gubernamentales y el fin de la cubertura de los deficits de las empresas estatales mediante la impresión de dinero". Igualmente, hay que levantar los controles de precios todavia existentes. "Unicamente, con el fin de garantizar niveles de vida de subsistencia se propone el mantenimiento de mecanismos de racionamientos de productos básicos a precios subsidiados. A partir de estas cantidades mínimas, la adquisición adicional de esos bienes habrá de pagarse a precios de mercado en rublos".

Otra de las iniciales condiciones es la plena convertibilidad extra del rublo de manera que un tipo de cambio real haga posible la libre competencia de las empresas soviéticas en el mercado internacional, y viceversa. Los bienes importados servirán como la mejor senal para que las empresas soviéticas fijen sus precios internos y se disuada a las gigantes unidades de producción de no abusar de su poder monopólico. La misma norma de igualdad competitiva se aplicaria a las instituciones bancarias en la concesión de los préstamos, a tasas de interés reales, a empresas públicas o privadas, sin contemplaciones para empresas cuyo grado de solvencia no les permitiria acceder al mercado.

Un tema que exige mayor prudencia es el necesario proceso de privatización, que en principio convendria acelerar. Pero se trata frecuentemente de los "grandes gigantes empresariales", herencia de la pasada megalomania y hoy dia muy criticados por sus deseconomias externas y privilegio financieros. Como paso previo a la privatización se impone un régimen de parcelación, máxime donde se observa un claro poder monopólico. El Banco Mundial sef́ala que "El objetivo final de la reforma 
debe ser la privatización de casi todas las empresas.... Esta institución cifra en 47.000 las grandes empresas industriales, propiedad del Estado, con una media de 800 empleados, y en 215.000 las empresas cooperativas, que dan empleo a más de 5,2 millones de trabajadores". Yaulinski ha previsto que "para casi todas las grandes empresas será necesario un paso previo (a la privatización) de mercantilización; esto es, transferir el control efectivo de la burocracia a una estructura de dirección y control mercantil".

Problema conexo es la privatización y transferencia del complejo militar en industria ligera civil para 1993. Tarea nada fácil porque esa industria emplea a 15 millones de personas y suponen tal vez un $15 \%$ del PIB. El proceso a seguir sería "mediante el arrriendo de las plantas de producción, la venta directa a inversores nacionales o extranjeros, 0 mayoritariamente, vendiendo acciones de las empresas con privilegio de compra para los trabajadores". Discusión aparte es la conveniencia o no conveniencia de venta mayoritaria de las acciones a los propios trabajadores, dado que las experiencias de autogestión en otros paises (caso-Yugoeslavia) ha sido más bien decepcionante.

Entre las claúsulas del plan de ayuda a la URSS, un artículo importante es la selección y el control del destino de la ayuda. Un objetivo prioritario es cubrir el deficit de la balanza de pagos, mediante el financiamiento de importaciones de bienes de consumo y de componentes industriales escasos. Pero a partir del tercer año, la cubertura inicial será sustituida por préstamos destinados a aquellos sectores donde el capital extranjero se muestre reticente: transporte, comunicaciones y medio ambiente... Es claro que la materialización de este plan de ayuda dependerá en gran manera de la posición que adopten los EE.UU. Aunque más alejados geográficamente, no serán ellos los menos favorecidos con toda la reconversión soviética. Aqui el papel de M. Gorbachov es de primera importancia, dado su prestigio y credibilidad occidental.

El programa de Yaulinski, siguiendo los lineamientos de Shatalin, y con el visto bueno del FMI y el Banco Mundial, sigue la línea de las precondiciones mencionadas. Se consagra la propiedad privada, se aboga por la separación del presupuesto central y el de las repúblicas. Considera básico la reforma del sistema financiero, el recorte del gasto público, la liberalización de los precios, exceptuando algunos bienes como el petróleo, el gas, el acero, el pan, la carne, el azúcar, la leche y los libros de texto de los escolares... Si bien persigue los mismos objetivos que Shatalin, con todo fija unos plazos más amplios para realizar las reformas, y requiere de una ayuda occidental de unos $\$ 20.000-$ $\$ 30.000$ millones, minimo en los tres primeros ańos. Los mayores pla- 
zos y la masiva ayuda buscan apaciguar las posibles protestas populares que emergen con la privatización de las empresas estatales y el recorte de subvenciones a unidades de producción deficitarias, que requieren de un cierre infnediato. En todos estos programas se repite la misma rutina: absorber el exceso de liquidez, reducir el deficit presupuestario, moderar la expansión de crédito y controlar los salarios para evitar la espiral inflacionista". ${ }^{29}$ Aunque nuestras circunstancias son muy diversas a las aquí comentadas, o la receta económica nos suena a "menú de la casa".

Una forma de cerrar este apartado es escuchar el comienzo del programa conciliador de A. Aganbegian, a modo de diagnóstico de la situación inicial a reformular. "El sistema administrativo de manejo de la economia de la URSS, con su prolongado dominio, ha tenido profundas consecuencias para el país. Las inversiones industriales y el gasto militar predominaban en la estructura del PTB, mientras que el financiamiento del bienestar del pueblo y el desarrollo social dependian del llamado principio del residuo. La perestroika heredó un presupuesto público deficitario, un gran excedente de dinero en manos de la población, no respaldado por suficientes bienes de consumo, escasez de múltiples productos en el mercado, amplia insatisfacción por las condiciones de la vivienda y una situación desastrosa en el campo de los servicios de la salud, la educación y las pensiones. Durante la perestroika se ha preparado una estrategia fundamentalmente nueva de desarrollo socioeconómico; concentrar los esfuerzos en elevar el nivel de vida del pueblo, insisitir en lo cualitativo (mayor eficiencia y mejor calidad) y no sólo en lo cuantitativo, acelerando el progreso científico-técnico; reformar de manera radical la gestión económica, sustituir el sistema administrativo gerencial por los mecanismos de mercado, y estimular, por medio de la apertura, la participación de la economía soviética en los mercados mundiales".... ${ }^{30} \mathrm{Si}$ no todo, si una buena parte de lo que aqui se dice nos describe a nosotros! ¿Qué harán ellos y qué haremos nosotros?

\section{VIII. "La nueva economia"}

¿Por qué este título? En la década de 1920 E. Preobranzhensky presenta su programa de reestructuración económica en la URSS bajo el nombre de "La Nueva Economia"31 Eran los años de la primera pe-

29. "100.000 millones de \$ para a URSS". El Pais; 7-7-91; p. 2 "La vía rusa al capitalismo". El Pais; 1-9-991; pp. 3 y 4.

30. Un resumen del plan-Agabegian se halla en ECA: julio-agosto 1991; pp. 705-709.

31. Preobranzhensky E.:: " La Nueva Economia. Ed. ERA. México, 1974. 
restroika; la palabra es utilizada ya entonces para introducir la Nueva Política Economia (NEP) de Lenin. ${ }^{32}$ Setenta anos más tarde reeditamos el título, pero con otro contenido. E. Preobranzhensky y N. Bhukarin, los dos grandes economistas de la reforma, ya fueron fusilados por Estalin en las purgas de 1936 y 1937.

Ironias de la historia; ahora es el FMI y el Banco Mundial quienes han hecho el diagnóstico y las sugerencias de la nueva economia de la URSS. ¿Podra ser éste el patrón de la nueva-economia?. Recientes manifestaciones externas parecerian confirmarlo. "La URSS acepta las condiciones del Grupo de los Siete (G-7) a cambio de ayuda" (14-1091). "La Unión Soviética acepta las condiciones de los paises ricos para transformar su economia" (14-10-91) "Los siete grandes ayudarán a la URSS en su reforma económica "La URSS acepta el plan de estabilización de corte latinoamericano para salvar el país" (17-10-91) "La misión del G-7 llegará a Moscú en dos semanas para impulsar su total transformación económica" (17-10-91)...

"La URSS está dispuesta a aceptar un plan de estabilización de corte latinoamericano y a asumir cuantos sacrificios sean necesarios para impulsar su reconstrucción económica, según anunció ayer Grigori Yaulinski --primer responsable de la economia soviética desde el golpe de estado- er el foro de la asamblea del FMI, que se celebra èn Bangkock...." ${ }^{33} \mathrm{El}$ redactor del diario El Pais, presente en esta reunión comenta desde Bangkock: "Todos los paises que han llegado al FMI en busca de apoyo saben cuál es la receta: o te ajustas a te ajustamos. G. Yaulinski no ha querido esperar a la segunda via. Ha traido un duro programa bajo el brazo, del que reconoce que "aún no cuenta con el acuerdo de las repúblicas, pero sobre el que hay - -dice - la compresión de que es necesario".

El plan establece tres etapas. La primera, la actual, se compone de la firma del Tratado de la Unión y su desarrollo. Esto último con la supervisión del FMI, el Banco Mundial y la OCDE. La segunda etapa contempla cinco paquetes de medidas de ajuste. Aunque implícitamente han sido mensionadas en el apartado anterior, ahora lo esquematizamos en cuanto compromisos adquiridos.

1) Estabilización macroeconómica. Esto significa implantar severas

32. Ibisate Foo. J.: "Perestroika: nuevas ideas para mi pais y el mundo. ECA. Mayo-1988; pp. 360-362.

- "La postperestroika en el bloque socialista". ECA. abril-mayo 1990; pp. $299 .$.

33. "La misión del G-7 llegará a Moscú en 15 dias". El Pals. 17-10-91; p. 57. 
políticas monetaria y fiscal, reducir la inflación con el control de la cantidad de dinero en circulación y la reducción del deficit público. Esto último se logrará, por el lado de los ingresos, con la subida de los impuestos indirectos y el agravamiento de las sanciones para los que evaden los impuestos, y desde el lado de los gastos, con la congelación de los programas sociales y el desmantelamiento de los gastos militares.

2) La liberalización de las relaciones económicas. Esto significa que el Estado abandonará (¿voluntariamente?) las funciones de director de empresa, reducirá los subsidios e implementará nuevos impuestos. También implica la liberalización de los precios, la reforma del mercado de trabajo y de los sistemas de contratación laboral.

3) Convertibilidad del rublo. La idea es avanzar en la liberalización del comercio internacional y para ello el rublo debe cotizar en los mercados de cambio. Como paso precio -dice Yaulinski- hará falta una fuerte devaluación que compense la falta de competitividad de los productos soviéticos.

4) Privatización. Antes de poner en venta la URSS y las repúblicas Yaulinski quiere instaurar una nueva regulación de los derechos de propiedad.

5) Medidas de transición. Yaulinski, en un intento de no fracasar con su impopular programa antes incluso de su puesta en marcha, ha intentado convencer al G-7 de la conveniencia de moderar la velocidad de los ajustes en el periodo de transición.

- La tercera y última etapa contempla la reforma de las instituciones, intensificar las privatizaciones y el desarrollo de los mercados financie$\operatorname{ros}^{\text {m34 }}$

A modo de paréntesis transcribimos algunas impresiones de los periodistas congregados en Bangkock.: "Yaulinski llegó a Bangkock, lo vieron y convenció. Este ucraniano de 39 anos se enfrentó primero a la mirada crítica del Grupo de los Siete, pasó después el examen de economia del FMI y se premió con el postre de un buen número de preguntas agresivas $\longrightarrow$ molestas - de los periodistas... Llegó con la ingrata tarea de reconocer ante los organismos internacionales y los paises más ricos del mundo que la URSS tiene problemas y necesita ayuda. Como primera prueba de humildad dijo: "no hemos venido a pecdir dinero, no se trata de eso"..., y se ha vuelto sin dinero. Yaulinski no ha esperado a que el FMI le imponga un plan de ajuste. "Sabemos to que

34. "Yaulinski se ha comprometido ante el FMI a realizar un duro plan de ajuste". El Pais; 17-10-91; p. 57. 
tenemos que hacer y tenemos un plan"... Pocos dirigentes occidentales habrian soportado con la misma calma el exhaustivo interrogatorio a que le sometió la Prensa.... El potencial nuclear de la URSS suscitó varios comentarios hostiles. Cuando se le preguntó por el peligro futuro de ese armamento, si se complica la situación política, Yaulinski respondió: "Lo siento, pero no soy Hitchcock; no intentaré averiguar lo que podria llegar a pasar"... La última pregunta solicitaba la posibilidad de una guerra civil en la URSS; la respuesta fué: "muchas gracias; hasta otra ocasión"... ${ }^{35}$

Este paréntesis periodístico es un puente tendido a una reflexión por etapas sobre las dificultades económicas de la transición: una potencia nuclear se ve en peligro de una guerra civil. Se sugieren tres reflexiones en cadena. En primer lugar, la reforma económica de la URSS, que Gorbachov califica de "revolución", pretende rehacer en sentido contrario las transformaciones económicas implantadas luego de la revolución de 1917. En las discusiones entre N. Bukharin y E. Preobrazhensky en torno a "La Nueva Economia", dos eran las tesis en litigio: cómo transformar una economia agricola retrasada en economia industrial, con visos de potencia bélica, y cómo asegurar el financiamiento de su desarrollo autosostenido en un medio ambiente hostil y de bloqueo externo. Setenta anos más tarde la revolución económica tiene que rehacer el camino en sentido bastante opuesto: ¿cómo transformar una economia bélico-militar y una potencia nuclear en una economía civil, en una economía de consumo social y en una agricultura capaz de alimentar a su población sin ayudas externas?. La URSS, por su ideologia (Teoria de la coexistencia Pacífica: ECA; abril-mayo, 1990; pp. 307-310) se deslizó en el mismo error en que también erraron otras potencias del primer mundo (por su semejante ideologia de la coexistencia Pacifica), de querer imponerse y convencer por sus economias bélico-militares. La historia nos ensefia que la economia militar puede vencer, pero no puede convencer, además de que arruina y deja internamente endeudado a los que pretenden convencer. Ahora resulta que la guerra civil puede nacer del exorbitante gasto y dedicacion militar; y si no la guerra civil, por lo menos las dificultades a la transición económica.

La segunda etapa de la reforma económica la planteamos en forma de pregunta: ¿significan todos tos compromisos ante el FMI y todos los ajustes mencionados que la URSS avanza hacia una economia de mercado? Digamos algo más elemental: significan simplemente que la URSS avanza hacia una economia o que optan por hacer "economia" en singular y en plural. Todos los analistas del bloque-Este, a comenzar

35. "No soy Alfred Hitchcock". El Pais; 17-10-91; p. 57. 
por los socialistas occidentales y los mejores pensadores soviéticos, coinciden en reafirmar que en la URSS no ha existido propiamente una verdadera economia y sobre todo no una economia social. Un pais de abundantes recursos materiales, desoyendo a sus mejores y grandes economistas, en virtud de otra normativa y otra dirigencia, llegó a planificar los mayores derroches macro y microeconómicos hasta topar con los límites de la escasez y el agotamiento. Todos los intentos que, a partir de 1930, década tras década hicieron economistas e ingenieros para la "buena administración de la casa" (=economia) fueron desoidos y perseguidos por la nomeklatura imperante, que se arrogó el privilegio de querer ser al mismo tiempo plan y mercado (ECA: mayo-1988; pp. 360-374), transformando a las empresas en sumisas unidades de producción, a la población en espectador del consumo. Se reprimieron todas las propuestas técnicas por introducir el cálculo económico, la optimización de los recursos y los esquemas de economia descentralizada y socialmente participada en las décadas de 1930-1940-1950-1960 hasta la actual Perestroika de 1985. Leyendo en diagonal los setenta anos de la historia soviética podemos concluir que es una historia sin economía.

Dos testimonios sirven a avalar esta tesis. Hace veinte anos el inspirador de la tronchada Primavera de Praga, 1968, Ota Sik, escribia: "desde el momento en que la burocracia y la corrupción crecen dentro del partido, crece el número de mediocres e inescrupulosos en sus filas, mientras que la gente con cierta conciencia crítica se aleja de él. En la cúspide se va desarrollando una burocracia a la defensiva contra toda crítica que en un modelo más descentralizado pudiera venir del mercado, del sistema de precios, de la competencia empresarial. Como se sienten incompetentes se cierran ante cualquier discusión y se refugian en medio de trabas burocráticas. Se cubren con una malentendida ortodoxia, que ellos mismos crean, condenando al mercado, a los precios y a la competencia empresarial como mecanismos antisociales. Deforman el propio concepto de propiedad, confundiendo la propiedad social con la propiedad siempre creciente del Estado y extraida de la plusvalia del trabajo. Tienen miedo de cuanto les puede hacer competencia y tienen miedo al pueblo, gracias al cual viven. Cada vez más dejan de pensar y de creer en el pueblo y cada vez más el pueblo deja de creer en el partido"36 Por esos mismos anos un grupo de economistas chechoeslovacos, analizando las matrices intersectoriales de las economias capitalistas y socialistas, mostraban que la participación de los salarios en el

36. Sik Ota: "Argumentos para una tercera via: ni capitalismo, ni comunismo soviético". Ed. Dopesa. Barcelona, 1975; p. 141. 
valor agregado era sensiblemente mayor en las primeras, mientras que la tasa de plusvalía sobre salarios era sensiblemente mayor en las segundas. ${ }^{37}$

El segundo testimonio es más reciente y bien autorizado. $\mathbf{N}$. Petrakov, congresista, economista acreditado, coautor con Shatalin del Plan de los 500 dias y miembro del grupo Unión Democrática. Comenta en el Foro de Moscú, 1989: ¿qué es socialismo? "El socialismo es una concepción del mundo, un concepto muy amplio del valor de la persona; es una visión de la sociedad que da protección social a la persona, que no sólo protege su libertad, sino que le da una garantía de satisfacción al margen de la aportación del individuo al desarrollo económico del país. Por eso yo pienso que el mercado, como forma de penetración de la democracia socialista en la economia, es nuestra única posibilidad. EI mercado y el socialismo son dos conceptos compatibles, y yo considero que muchas ideas socialistas no pueden realizarse fuera del mercado. Ahora nos enfrentamos al problema de introducir el mercado cuando se está desintegrando el sistema financiero soviético; es decir, cuando no podemos ir del mercado al mercado". (Realidad E. S.; enero-febrero 1990; pp. 26-27).

Estos dos testimonios, distantes veinte anos, de dos acreditados reformadores socialistas nos confirman, a la vez, de las dificultades pasadas y presentes para poder conformar una economia de mercado socialista, porque el mercado es parte esencial del socialismo democrático. Los socialismos de Europa Occidental no son economias anti-mercado:" conservadores en lo económico, socialdemócratas en lo demás". Por ello hemos dicho que todas estas reformas y reajustes son, en primer lugar, un intento de hacer economia y hacer mercado; el calificativo dependerá de la inspiración que los nuevos directivos, la nueva empresa y el nuevo pueblo logren injertarle. $Y$ aqui nace un nuevo problema.

Quien haya leido las 25 primeras páginas de Perestroika o haya tenido la oportunidad de conocer el Informe el Pleno del Partido de $\mathrm{M}$. Gorbachov, no se extranará cuando oiga testimonios, no de turistas transitorios, sino de residentes más permanentes, que día a día destacan un nuevo fenómeno antisocial: la corrupción que salta a la calle. Con la pérdida de los primitivos valores socialistas, con la degeneración creciente del partido, están proliferando los aprovechados, los especuladores de la escasez y más sencillamente los explotadores de sus conciudadanos. La corrupción política se ha revestido de corrupción

37. Sik Ota: "La troise'me voie". Ed. Gallimard. Paris; 1974; pp. 240-246. 
económica. Muchos grupos se están preparando, de esta forma, para transferirse a una economia de mercado:" ¿cuál mercado?....

Con fecha de 23 de octubre, el historiador $\mathrm{G}$. Jackson, en un artículo titulado "Los límites morales del Capitalismo", luego de hacer un arqueo del comportamiento moral capitalista en cuatro de los cinco continentes, llega a la siguiente conclusión: los problemas de la transición de economia planificada a economia de mercado no son tan dificiles porque no haya experiencias precedentes de la reconversión. Las ideas y los programas presentados por los brillantes economistas soviéticos, con el apoyo occidental, hacen posible acelerar la transición. El problema está en que el colapso económico y político ha degenerado en una extendida depravación de los valores cívicos. "El colapso económico soviético no sólo ha desembocado en un caos. Inmediatamente ha reforzado una mafia, ya existente, que durante décadas ha controlado en forma progrresiva la asignación de los recursos madereros y minerales, el transporte (o la falta del mismo) de alimentos a las ciudades y el desvio de todo tipo de productos, tanto industriales como agricolas, del sistema de distribución oficial al mercado negro. Y en medio de la confusión de los dos o tres últimos años, ha tenido lugar un rápido ascenso de todo tipo de corrupción económica y social. Muchas de las nuevas cooperativas están dominadas por especuladores que se apresuran a monopolizar los servicios y las tecnologias más esenciales. Gran parte de la privatización de la industria ha significado simplemente que los "apparatchiki" del partido han podido adquirir títulos privados de las factorias y otras empresas que ellos habian administrado mal como oficiales nombrados por el partido. Nuevos millonarios, idénticos a los gansteres occidentales 0 a los dictadores del tercer mundo que les precedieron, han abierto cuentas en bancos suizos. Tanto la prensa rusa como la occidental a menudo relatan historias que recuerdan a las de la Alemania-Año cero, de 1945-46: sexo a cambio de cigarrillos, medias de seda o droga; importes de taxis pagados en dólares, de modo que permiten al taxista ganar más en unas pocas horas de lo que la mayoria de los trabajadores soviéticos ganan en un mes; mercado negro de armas de alta tecnologia, etcetera..."

"En lo que a mí respecta, no veo ninguna salida puramente pragmática para el actual estanciamiento. El desarrollo de las economias de mercado descentralizadas es una condición necesaria, pero en modo alguno suficiente, y sin él sabemos que las injusticias y la ineficiencia económicas continuarán de modo inevitable. Pero el capitalismo salvaje que en la actualidad está creciendo en la anterior Unión Soviética, junto con las mafias, la corrupción moral y financiara, la monopolización de los escasos recursos naturales y la exportación de la riqueza nacional a 
anónimas cuentas bancarias en Suiza y en el caribe, no va a proporcionar el marco justo o estable, necesario para un nueva sociedad"... La tesis de G. Jackson es que estas mismas lacras y senales de corrupción las podemos encontrar (el autor hace un periplo geográfico) en el mundo capitalista árabe, asiático, africano y por supuesto latinoamericano. EI problema de fondo no es mercado o no mercado, sino el de los valores 0 antivalores sociales.

"No podemos cerrar los ojos ante las obvias faltas del capitalismo, sólo porque el socialismo haya fracasado.... Otras alternativas, tanto evolucionarias como revolucionarias, sin duda se desarrollarán en el futuro si no se establecen estos límites a los que me he referido en el capitalismo de mercado. $Y$ me refiero a ellos como una dimensión moral porque su justificación no es esencialmente económica, aunque beneficiaria a la mayoria de los sectores de la economia. Su principal justificación es la minima solidaridad humana, sin la cual los ricos se enriquecerian más y los pobres empobrecerán hasta que la esencia de la civilización desarrollada sea destruída". ${ }^{38}$

Este valioso comentario nos ayuda a responder a la pregunta inicial: "¿Camina la URSS hacia una economía de mercado?" la respuesta es otra pregunta: ¿hacia qué clase de economia de mercado? Todos los ajustes comprometidos por Yaulinski en Bangkock deben ser iniciados y desarrollados para emerger del caos hacia una sociedad económica. Sobre la corrupcón se suma otro obstáculo: ¿cómo será la nueva economia, integrada o desintegrada? El centralismo septagenario ha generado la antitesis separatista, que es algo más que nacionalista. Este parece ser el problema más candente, pese a que la solución haya que buscarla en el frio y largo invierno ruso. EI Presidente de la URSS y los Presidentes de las Repúblicas Soberanas discuten sucesivamente el Tratado de la Unión Económica y luego el Tratado de la Unión Política. Al frente del escenario ya no está la efigie de Lenín, sino el nuevo leivmotiv: "Unión de Estados Soberanos".

A los dos meses del golpe, 18 octubre-91, ocho de las diez repúblicas comprometidas han firmado un tratado económico; Ucrania y Azerbaijan se quedan al margen, aunque se espera su adhesión posterior. La primera tarea es reconstruir la "des-Unión Soviética", por lo menos con una mayoritaria unión económica. En la sesión de firma del tratado, con descorche de champán, M. Gorbachov hizo el brindis: "El hielo se ha roto. Comencemos..." Luego de estampadas las ocho firmas, B. Yeltsin advirtió que no habia que dejarse llevar de la euforia, y "que no

38. Jackson G.: "Limites morales del capitalismo". El País. 23-10-91; p.13. 
se nos suba el champan a la cabeza. Este acuerdo era muy necesario precisamente ahora, cuando tenemos por delante los largos y dificiles meses de invierno"... Por su parte, M. Gorbachov, que tanto ha bregado por salvar la Unión en una y otra forma, agregó: "El que hoy se haya dado tan importante paso, como es la firma de este tratado, testimonia que en la sociedad -y esto se refleja en las posiciones de los órganos del poder supremo y de los presidentes de las repúblicas- es muy fuerte el deseo de vivir juntos, resolver los problemas juntos, salir juntos de la crisis y emprender el camino del desarrollo dinámico en interés de todos nuestros pueblos". Los participantes a la fima del tratado económico recordaron inmediatamente que Gorbachov habia escrito estas mismas palabras, hace cuatro años, en su epilogo de Perestroika.

El Tratado de la Unión Económica declara que "La base para el progreso económico la constituyen la propiedad privada, la libre empresa y la competencia..." Cada una de las repúblicas deberá aplicar políticas comunes en las áreas "del sector empresarial, el mercado de productos y servicios, el transporte y la energia, los sistemas monetarios y bancarios, las finanzas, los impuestos, los precios, asi como los mercados de capitales y de trabajo". ${ }^{39}$ El tratado de la unión económica se firma para tres años, y 12 meses antes de cumplirse el plazo las repúblicas deciden renovarlo o reformarlo, asi como comunicar del retiro si alguna república lo decidiera. Hay una claúsula algo ambigua: "Para aplicar esta politica los miembros crean instituciones comunes con sus correspondientes facultades". La sensibilidad nacionalista es tan fuerte que algunos ven en este articulado un intento de restablecer antiguas estructuras del poder central.... No está resultando tan fácil la unión.

Terminado el acto, Gorbachov manifestó que desea lo antes posible dar curso al siguiente paso: la firma de una nueva Unión Politica. Para ello se ha hecho llegar el texto a los dirigentes de las repúblicas. Se preve o es posible esperar que el tratado de la Unión Política tenga menos miembros que la Unión económica. Por ello, tres dias más tarde, en la sesión de apertura del nuevo Parlamento Soviético, Gorbachov advirtió sobre la catástrofe de la desintegración. "Unos creen necesario mantener el antiguo estado supercentralizado y unitario; otros estiman que es suficiente una unión económica sin implicaciones políticas, e incluso hay quien piensa que la Unión ya no existe y es necesario continuar hasta el final el proceso de desintegración. Si cualquiera de estas tres concepciones es tomada como base de la política soviética, las consecuencias serán catastróficas para todos los pueblos, sin excepción 
y para las repúblicas tanto grandes como pequefas".40

En esa primera sesión los argumentos y las convicciones unionistas de $M$. Gorbachov fueron escuchados, dicen, con cierta apatia sin provocar un sólo aplauso... En cuanto estamos informados y mientras avanza este dificil debate, el propio $M$. Gorbachov ha exteriorizado su voluntad de dimitir como Presidente de lo que queda como Unión si fracasa su proyecto de integración nacional, que vendría a ser la aplicación de su primera gran tesis de Perestroika: todos somos interdependientes e internecesarios, de manera que los problemas de unos no pueden resolverse sin resolver los problemas de los otros.

\section{IX. "La Inconclusa de M. Gorbachov}

El golpe de agosto ha venido a confirmar que la gran obra de $M$. Gorbachov todavia esta inconclusa. Esto no significa ningun fracaso, sino un gran triunfo; $M$. Gorbachov es y será un hombre que pasará a la historia porque ha contribuido a cambiar la historia del mundo. Cuando en 1988 leimos y releimo sus "nuevas ideas para mi pais y el mundo" entendimos que con Gorbachov y sus inspiradores se iniciaba una revolución pacífica. Como toda revolución pacífica tendria sus admiradores y sus depredadores. Era de esperar que él seria un hombre muy admirado fuera y muy criticado dentro. Un hombre admirado fuera porque queria poner fin a setenta anos de tensiones entre sistemas opuestos, con su "mano-tendida" y su apremiante ofensiva contra la mania armamentística. En un mundo de tensiones se alzó como un gran pacifista. espontáneamente se le nombró "el hombre de los EE.UU. 1988" y se le concedió el Premio-Nöbel de la Paz-1990.

Al interior de la URSS muchos criticaron este reconocimiento, y también era lógica esta reacción; su revolución pacífica no sólo era antibélica en lo internacionalmente militar, sino prodemocrática en lo político, en lo económico, en lo social y en lo humano-cultural. Al interior de la URSS la Perestroika era vista como el premio-Nöbel a la guerra y al cambio de la inercia de setenta anos de rigidez centralista en todos los ámbitos de la convivencia social. Gorbachov y su equipo arriesgaron y se atrevieron a decir lo que nunca en el Este ni en el Oeste-se habia dicho: la verdad y toda la verdad. Es interesante escuchar hoy que quienes lo prepararon (Y. Andropov...) y lo propusieron al cargo de Secretario General (Gromiko...) presentian que este hombre tenaz y convencedor llevaria sus ideas hasta el final, por encima de todas las

40. "Gorbachov insta a mantener la Unión Soviética como potencia muncial". El Correo Español. 22-10-91; p. 17. 
dificultades. En seis años ha hecho evolucionar tanto las cosas que, pese al golpe o a los golpe, es imposible retroceder a las visperas de 1985.

Al interior de la URSS y al interior de Europa Gorbachov ha sido el gran defensor de la Unión y de la unidad. Para lograr la unión libre era preciso desmontar el mosaico quebradizo de la unión forzada. De hecho, la unión impuesto presentaba ya todos los sintomas de la "desUnión Soviética". Operación más difícil que dislocar unos huecos mal colocados y reinstalarlos en sus junturas naturales. Es el actual debate en torno al Tratado de la Unión económica y Unión Política Gorbachov resintió en la URSS el problema de las nacionalidades de vieja raigambre, pero que transciende las fronteras de la URSS. Europa, el "hogarcomún" del capítulo $6^{2}$ de Perestroika, es un ideal de Gorbachov, porque Europa tampoco es un hogar común; el rebrote de las nacionalidades, de las etnias, de la xenofobia, de los "unidos" que no se quieran, del opulento Occidente que mira con recelo al pobre oriental (alemanias, Yugoeslavia, Albania...) esa Europa es un posible polvorín. El problema de las nacionalidades es tan movedizo que no se le puede tapar con el tapete del gran mercado europeo. Por debajo de los millonarios créditos e inversiones subyacen resquemores de minorias marginadas.

Tampoco el mapa es tan liso en el Medio Oriente y el oro-verde no unifica sino divide a estas regiones; vibran los conflictos étnico-religiosos que se han destapado, en este año, desde la guerra de Irak-Kuwait hasta la guerra de la Cumbre de Madrid. Asi podemos recorrer otras naciones de otros tres continentes, donde al final de siglo se vuelve a dar una segunda oleada de sacudidas nacionalistas. La revolución pacifica de Gorbachov también es democrática al plantear el consorcio de las naciones. Desde el prólogo de Perestoika él ha predicado la política del diálogo y, a modo de ejemplo, el capítulo séptimo es el recuento de sus persuasivas relaciones con los EE.UU. EI ha sido un impulsor del diálogo, mediando hasta el último minuto para detener el ataque a Irak, o más recientemente abandonando su nación en crisis para catalizar la paz en la Cumbre de Madrid. Con Gorbachov hemos aprendido que los modales imperialistas no son el mejor sistema, a largo plazo, para mantener la unión. No se deberia recurrir ya a la tormenta del desiento o al tormento de los ajustes para dominar a los inconformes 0 a los paises más pobres.

Sobre todo la revolución pacifica de Gorbachov ha quedado inconclusa en Occidente, porque al Occidente le cuesta mucho escribir su Perestroika. Más bien lo contrario. Frente a la crisis del Este se siente triunfante y justificado. Triunfó la democracia del mercado, donde las 
leyes son fuerzas y ajustes; visión ingenieril de las relaciones sociales. La mano invisible de Adam Smith se llama FMI, con más poder que las Naciones Unidas, como lo comienza a sentir la propia URSS. No significa esto que la URSS no requiere de la más profunda transformación económica, por todo lo aqui dicho; pero nos queda la esperanza de que si la URSS es finalmente integrado en estas Instituciones Internacionales pueda aportar su giro social, por lo menos para aliviar el peso de la deuda externa tal como aparece en la parte final de sus programas de reformas económicas. Inconclusa la ensenanza o la tesis de Gorbachov, para quien las grandes potencias deben conjugar sus poderes para solventar el desarrollo de ese océano del Tercer-Mundo: "todos los paises tienen sus problemas. Pero los paises del Tercer-Mundo los tienen cien veces más y eso debe ser tomado en consideración" (p. 158). Gorbachov nos ha presentado una visión más social: "¿cómo vemos el mundo actual?"; pero el Occidente sigue mirando el mundo en horizontal y a nivel de hemisferio Norte: el Este camina hacia el Oeste y el Oeste avanza hacia el Este. Pero esa proyección es bastante mercantilista e inversionista cuando se presenta como "the grand bargain".

El Este necesita realmente del Oeste, como lo prueban los datos estadisticos del presente comentario; pero el opulento Occidente deberia animarse a escribir su propia Perestroika: ¿cómo se ve y como ve al mundo actual? Porque sin duda la historia va a quedar más agradecida a quien escribió la Perestroika - la corone o no la corone con éxito personal- que a quien promovió "La tormenta del desierto".

Lic. Fco. Javier Ibisate 